\title{
Artículos
}

\section{La fecundidad de los grupos étnicos en México}

\section{The fertility of ethnic groups in Mexico}

\author{
Germán Vázquez Sandrin*
}

\begin{abstract}
Resumen
El artículo cumple con dos propósitos fundamentales: por un lado, mostrar la variedad de los niveles de fecundidad indígena a la escala más desagregada posible en el México contemporáneo y, por otro, validar la hipótesis que considera que al menos algunos grupos étnicos mantienen una fecundidad propia.

Entre los resultados del artículo se muestra una diversidad interétnica de niveles de fecundidad que varian entre 1.7 y 5.6 hijos por mujer, y se identificaron 25 grupos indigenas cuya fecundidad tiene una especificidad cultural o de otra naturaleza, los cuales son relevantes en la explicación de la fecundidad en México.
\end{abstract}

Palabras clave: grupo étnico; indígena; fecundidad; México.

\begin{abstract}
The article serves two main purposes: on the one hand, it shows the variety of levels of indigenous fertility at the most disaggregated scale possible in contemporary Mexico; and, on the other, it validates the hypothesis that considers that at least some ethnic groups maintain their own fertility.

The results of the article show an interethnic diversity of fertility levels that vary between 1.7 and 5.6 children per woman, and identify 25 indigenous groups whose fertility has a cultural or other kind of specificity, which are relevant in explaining fertility in Mexico.
\end{abstract}

Keywords: ethnic group; indigenous; fertility; Mexico.

* Universidad Autónoma del Estado de Hidalgo. Dirección postal: Carretera Pachuca Actopan km. 4.5, San Cayetano, 42084, Pachuca, Hidalgo, México. Correo electrónico: gevaz quez@uaeh.edu.mx ORCID: https://orcid.org/0000-0003-4319-7707

Nota del autor: Agradezco el apoyo del Programa Internacional de Cooperación Científica "Naissances mexicaines" (PICS-Nacimex) del Centro Nacional de Investigación Científica (CNRS, por sus siglas en francés). En este marco, el presente artículo fue producido en buena medida durante mi estancia de investigación en el Cresppa-GTM, con el apoyo de Labex iPOPs. Agradezco a Carole Brugeilles por su gestión para recibir el apoyo mencionado. 


\section{Introducción}

Para hablar de grupos étnicos es de utilidad primero intentar brevemente agregar cierta claridad a un conjunto de categorías relacionadas entre sí: diferencia social, identidad social, indígena, etnia y grupo etnolingüístico (se presentan ordenadas de lo general a lo particular).

El contexto más general del cual es necesario partir es la diferencia social de la otredad, la cual encarna en distintos tipos de sociedades a través de las razas, las clases sociales, las identidades sociales y las religiones, y dependiendo de la forma de administrarla, puede ser ordenada de forma jerárquica en términos de superioridad y subordinación. Ulrich Beck (2014) identifica cinco formas de administrar la diferencia social: racismo, universalismo, nacionalismo, multiculturalismo y cosmopolitismo. Si bien Beck no hace un análisis exhaustivo de la etnia en la descripción de cada una de ellas, de cualquier forma, establece un marco de referencia revelador de cómo adquiere distintos significados según la perspectiva que se trate.

El racismo parte de un principio de ordenación vertical en el cual la integración de la diferencia social se realiza en una relación jerárquica de superioridad y subordinación. Los "otros" pueden llegar a ser vistos como bárbaros desprovistos de derechos.

El universalismo, por su parte, reemplaza la pluralidad de normas, de clases, de identidades étnicas y de religiones por una norma unificada; es una forma típicamente moderna de administrar la diferencia.

El nacionalismo sigue una lógica discriminatoria de la diferencia, pero en lugar de la distinción entre lo superior y lo inferior, lo hace entre lo interior y lo exterior. Hacia el interior, el nacionalismo busca disolver las diferencias y promover normas uniformes (lo cual comparte con el universalismo). Al exterior, en cambio, la otredad es preservada y acentuada.

El multiculturalismo hace referencia únicamente a las categorías colectivas de la diferencia; se aplica en principio a los grupos (más o menos) homogéneos y luego los moldea en el marco del Estado-Nación. En este sentido, el multiculturalismo se opone al mismo tiempo al transnacionalismo $\mathrm{y}$ al individualismo.

El cosmopolitismo, finalmente, reconoce la diferencia como un principio intelectual y social para la vida interior y exterior de la comunidad. No busca disolver u ordenar jerárquicamente las diferencias. Al contrario, las acepta en sí mismas y les otorga el mismo valor positivo. Le da un lugar a los excluidos por la diferencia jerárquica y la igualdad universal, presentando a los "otros" como diferentes e iguales. Este principio está basado en que la particularidad de los "otros" puede hacer referencia a los colectivos o a 
los individuos. En lo que toca a la interpretación colectiva del cosmopolitismo, ésta es difícilmente discernible del multiculturalismo. Cabe explicar que el cosmopolitismo es un enfoque en construcción que aún no puede decirse que tenga un referente real y acabado en alguna parte del mundo. México es un país legalmente autorreconocido como pluricultural desde el año 1992, pero en la práctica puede decirse que se encuentra en algún punto entre el nacionalismo y el multiculturalismo.

La identidad social:

[...] gira en torno a la idea de una distintividad cualitativa socialmente situada y basada en tres criterios básicos: una red de pertenencias sociales (identidad de rol o de pertenencia), un sistema de atributos distintivos (identidad "caracteriológica") y la narrativa de una biografía incanjeable ("identidad íntima" o identidad biográfica) o de una memoria colectiva [Giménez, 1997, p. 9].

Las identidades sociales incluyen a las identidades étnicas, como la indígena, menonita, hispano, manouche, etc. Es en el orden de las identidades sociales y étnicas en particular, que la globalización ha influido de forma muy notable, disolviendo las identidades comunitarias creadas previamente; ello ha llevado a los individuos que quedan en la anomia y en el desamparo a crear nuevas identidades y nuevas comunidades que, por el contrario, son más líquidas y cambiantes en el tiempo. De este modo, se llega a la conformación de comunidades líquidas, volátiles, transitorias, exentas de territorialidad, que nacen en el contexto de la globalización (Bauman, citado por Díaz-Polanco, 2009). Ciertamente, estas otras identidades surgen para crear nuevas comunidades, y son resultado del debilitamiento o colapso de las viejas comunidades por el efecto de la globalización, que exacerba el individualismo, la anomia y la pérdida de tejidos sociales (Díaz-Polanco, 2009).

Es importante mencionar que aun las identidades y comunidades indígenas se encuentran bajo la presión disolvente de la globalización. En México, las identidades étnicas reconocidas son únicamente las indígenas, invisibilizándose así a todas las demás. La categoría indígena es una categoría panétnica (Gros, 2012, pp. 105-106), es decir, es un saldo de todas las etnias; por ello, al hablar de indígena no hablamos de una cultura, sino de muchas culturas. Indígena se desagrega en pueblos, comunidades y etnias (o grupos étnicos). Para pueblos y comunidades indígenas, la Constitución Política provee una definición, pero para grupos étnicos no. Según el artículo 2 de la Constitución Política Mexicana: 
Pueblos indígenas [...] son aquellos que descienden de poblaciones que habitaban en el territorio actual del país al iniciarse la colonización y que conservan sus propias instituciones sociales, económicas, culturales y políticas, o parte de ellas. La conciencia de su identidad indígena deberá ser criterio fundamental para determinar a quienes se aplican las disposiciones sobre pueblos indígenas. Son comunidades integrantes de un pueblo indígena, aquellas que formen una unidad social, económica y cultural, asentadas en un territorio y que reconocen autoridades propias de acuerdo con sus usos y costumbres [Cámara de Diputados, 2019].

Cabe mencionar que el origen de esta definición fue resultado de una amplia investigación a cargo del relator especial José R. Martínez-Cobo. En el capítulo Conclusiones del informe final del estudio del problema de la discriminación contra las poblaciones indigenas, también conocido como reporte Martínez-Cobo, se define a las poblaciones indígenas de la siguiente manera:

Son comunidades, pueblos y naciones indígenas los que, teniendo una continuidad histórica con las sociedades anteriores a la invasión y precoloniales que se desarrollaron en sus territorios, se consideran distintos de otros sectores de las sociedades que ahora prevalecen en esos territorios o en partes de ellos. Constituyen ahora sectores no dominantes de la sociedad y tienen la determinación de preservar, desarrollar y transmitir a futuras generaciones sus territorios ancestrales y su identidad étnica como base de su existencia continuada como pueblos, de acuerdo con sus propios patrones culturales, sus instituciones sociales y sistemas legales.

Esa continuidad histórica puede consistir en la continuación, durante un periodo prolongado que llegue hasta el presente, de uno o más de los siguientes factores:

a) ocupación de las tierras ancestrales o al menos de parte de ellas;

b) ascendencia común con los ocupantes originales de esas tierras;

c) cultura en general, o en ciertas manifestaciones específicas (tales como religión, vida bajo un sistema tribal, pertenencia a una comunidad indígena, trajes, medios de vida, estilo de vida, etc.);

d) idioma (ya sea que se utilice como lengua única, como lengua materna, como medio habitual de comunicación en el hogar o en la familia, o como lengua principal, preferida, habitual, general o normal);

e) residencia en ciertas partes del país o en ciertas regiones del mundo;

f) otros factores pertinentes.

Desde el punto de vista individual, se entiende por persona indígena todo individuo que pertenece a esas poblaciones indígenas por autoidentificación como indígena (conciencia de grupo) y es reconocido y aceptado por esas poblaciones como uno de sus miembros (aceptación por el grupo). 
Eso preserva para dichas comunidades "el derecho y el poder soberanos de decidir quién pertenece a ellas, sin injerencia exterior" [United Nations, 1983, pp. 50-51].

De esta definición se deriva que la conciencia de la identidad indígena permite identificar a los individuos miembros de un pueblo indígena.

Etnia, grupo étnico y comunidad, según la bibliografía especializada, tienen un significado similar, sin embargo, su definición es un tanto nebulosa. Una etnia (o grupo étnico) es una forma organizativa y adscriptiva que en México puede equivaler a una comunidad (Bartolomé, 1997). Una comunidad, desde una visión "clásica", es un grupo relativamente cerrado, homogéneo y en permanente equilibrio (Erick Wolf, citado por Díaz-Polanco, 2009), aunque Dehouve (2001) considera que la comunidad se construye y reconstruye permanentemente a partir de la geopolítica, la relación de fuerzas y los mecanismos de negociación del Estado, donde el municipio es un ámbito clave.

Es importante no confundir etnia o grupo étnico con grupo etnolingüistico (es decir, con las poblaciones integradas por el conjunto de hablantes de variantes de una lengua o de diferentes lenguas de una misma familia lingüística) (Bartolomé, 1997, p. 54). El grupo etnolingüístico, si bien es un aspecto importante para la delimitación del grupo étnico porque representa un rasgo de la cultura compartida, ignora por completo la dimensión espacial que lo contiene. Un ejemplo clásico es el grupo etnolingüístico náhuatl, el más grande del país, que se encuentra fraccionado en múltiples grupos étnicos distribuidos en gran parte del territorio nacional. Por ello, las aproximaciones antropológicas que estudian a los grupos étnicos existentes en México distinguen al mismo tiempo la lengua y la demarcación territorial del grupo poblacional.

Es por lo anterior que la diversidad étnica en México está asociada estrechamente a la diversidad cultural indígena, en la que se privilegia la lengua como principal indicador, pero hasta ahora existen muy pocos ejemplos de estudios sociodemográficos que aborden la diversidad de los grupos étnicos de México considerando su demarcación territorial.

El avance en la producción estadística de las últimas décadas en México hace accesible información cada vez más desagregada, que permite observar unidades sociales y territoriales más pequeñas y posibilita descubrir la diversidad que escondían las categorías aglutinadoras que antaño eran las únicas accesibles, tales como "hablantes de lengua indígena".

En lo que toca a los estudios demográficos de la fecundidad, éstos se han beneficiado por el incremento en los tamaños de las muestras de las encuestas. Gracias a ello, entre otros avances, se tienen estimaciones más precisas de la 
fecundidad de los grupos etnolingüísticos ya conocidos; se puede estimar por vez primera la fecundidad de grupos de reducido tamaño; también es posible poner a prueba nuevamente hipótesis culturalistas, $\mathrm{y}$ es factible observar unidades territoriales y sociales más semejantes al grupo étnico.

Es sabido que la fecundidad de las mujeres hablantes de lengua indígena en México se encuentra en descenso, y que la transición de una fecundidad natural a una controlada en las mujeres residentes en municipios rurales (menores a 15000 habitantes) inició a mediados de los años 1980 y fue protagonizada por las mujeres nacidas entre 1958 y 1962; sin embargo, en dichos municipios la transición ha sido larga e incompleta y no se observa un claro y definitivo patrón de fecundidad controlada (Vázquez, 2010). Por su parte, en las mujeres hablantes de lengua indígena residentes en municipios urbanos (de 15000 y más habitantes), el cambio de patrón de la fecundidad de natural a controlada ocurre con anterioridad, a cargo de las mujeres nacidas entre 1953 y 1957, y su transición es más contundente en el control de su fecundidad (Vázquez, 2012). También es sabido que las tasas globales de fecundidad entre hablantes y no hablantes de lengua indígena tiende a la convergencia; es decir, que las brechas que las separan entre 1999 y 2014 van reduciéndose (Vázquez y Cenobio, 2017).

Ahora bien, en lo que respecta a los estudios de la fecundidad dirigidos a las distintas culturas indígenas, pueblos o etnias del conjunto del país, no hay mucho realizado. Los estudios existentes de este tipo enfrentan contradicciones. La categoría en la que están basados es la de grupos etnolingüísticos, que es la referente a la información que ofrece el Instituto Nacional de Estadística y Geografía (INEGI) de México a través de sus censos y encuestas. Es sabido que entre los 17 grupos etnolingüísticos más grandes de México se encuentra una elevada heterogeneidad de niveles de fecundidad en 2009.

Los valores más bajos los presentan los mayos, amuzgos de Guerrero y mixes con 2.5, 2.6 y 2.7 hijos promedio por mujer. Las tasas más altas son de los coras y huicholes, con 5.5 y 5.0 hijos promedio por mujer. Como se aprecia, las tasas globales de fecundidad de los coras son de más del doble de las de los mayos [Vázquez, 2013, p. 252].

Contrariamente a lo anterior, un estudio previo publicado por el Consejo Nacional de Población (Conapo), cuyas estimaciones fueron extraídas de la Encuesta Nacional de la Dinámica Demográfica (Enadid) 1997, encuentra poca variabilidad de la fecundidad entre los grupos etnolingüísticos, y concluye lo siguiente: 
A diferencia de la mortalidad infantil, donde hay mayor variación en los niveles de este fenómeno entre las etnias, la brecha en la tasa global de fecundidad es más estrecha: si bien oscila de 3.7 hijos en las chontales a 4.5 hijos en las tojolabales, en 18 etnias (amuzgo, chatino, chol, huichol, mazahua, mazateco, mixe, mixteco, náhuatl, otomí, popoluca, tarahumara, tepehuán, tlapaneco, totonaca, tzeltal, tzotzil y zoque) sólo fluctúa de 4.1 a 4.4 hijos [Partida y Solís, 1997, p. 77].

Por lo que toca a lo indígena como determinante de la fecundidad en México, también existen algunos resultados empíricos aparentemente contradictorios entre sí. Por una parte, con base en los datos de la Encuesta Nacional de Salud Reproductiva (Ensar) 2003, en México la categoría “indígena" (compuesta por la doble condición de hablar una lengua indígena y pertenecer a un grupo étnico) no pierde significancia estadística como determinante de la paridad, primero en un modelo de regresión lineal múltiple en el que se incluyó ser indígena como variable explicativa, y después en otros dos modelos del mismo tipo, uno para indígenas y otro para no indígenas, pero ambos filtrados a un estrato socioeconómico muy bajo (Chávez, Hernández, Menkes y González, 2007). Entre las conclusiones de dicho trabajo, los autores afirman:

[...] encontramos variaciones significativas en las variables que inciden en el comportamiento reproductivo de la población indígena y no indígena, aun controlando las distintas variables sociales y demográficas. Eso demuestra la existencia de valores culturales diferentes en las mujeres indígenas que afectan de manera notable su conducta reproductiva [Chávez, Hernández, Menkes y González, 2007, p. 58].

Por otra parte, con un modelo de regresión logística para datos longitudinales (conocido como el modelo de Allison), pero esta vez reducido al medio urbano derivado de la Encuesta Demográfica Retrospectiva (Eder) 2011, en la que la variable dependiente fue la ocurrencia de un nacimiento ocurrido en cada año en la biografía de los individuos y entre las variables independientes, se incluyeron cuatro categorías de identificación indígena (hablante de lengua indígena; autoadscrito a un pueblo indígena; con origen indígena; e indígena con base en la combinación de las categorías anteriores), así como variables de origen social de los padres, variables sociales y variables demográficas; se encontró que, al controlar por el origen social y las variables sociales del individuo, las cuatro categorías de identificación indígena pierden significancia estadística para explicar la fecundidad. Esto se corrobora para hombres y mujeres, con excepción de la población masculi- 
na identificada como indígena con base en la combinación de las otras tres categorías (Vázquez, 2016).

La tesis culturalista en México es aún el paradigma predominante en lo que respecta al posicionamiento a partir del cual mucha de la bibliografía en ciencias sociales, e incluso las personas en su vida cotidiana, se explican por qué los indígenas son diferentes a los no indígenas. Algunos de sus máximos exponentes han sido sin duda Guillermo Bonfil Batalla y Enrique Florescano. Esta tesis postula que la cultura es lo que ha hecho que los grupos étnicos puedan sobrevivir a partir de la resistencia frente a colonización u otras políticas que buscan integrarlos o desaparecerlos. La solidaridad y las costumbres son elementos básicos de la cultura de los grupos étnicos (Stavenhagen, 1992), así como la identidad, la memoria, la lengua y el territorio, entre otros.

En algunos análisis demográficos, esta teoría ha servido para explicar por qué una población puede tener un comportamiento demográfico específico y diferenciado, así como por qué ciertas tendencias de la fecundidad y estructuras familiares persisten en el tiempo (Cleland y Wilson, 1987; Knodel y Van de Walle, 1979). Algunas de las críticas a esta teoría se dirigen a las dificultades de conceptualizar la cultura (Kertzer, 1995; Hammel, 1990); otras consisten en que el culturalismo hace hincapié en la perdurabilidad de los pueblos indios, mientras que carece de elementos para explicar la dinámica de génesis y desaparición de los grupos indígenas.

En los últimos años, toda esta corriente culturalista pareciera sufrir fuertes resquebrajaduras, al mismo tiempo que surgen nuevas formas de medición de lo étnico que rompen las fronteras de la dimensión cultural, vista como un rasgo objetivo y externo, y ponen en evidencia su sentido líquido y posmoderno. Para empezar, un golpe al culturalismo consiste en la aceptación cada vez más extendida entre los términos de raza y etnia. Si bien está bastante extendida la idea de que lo racial se refiere a los rasgos físicos y lo étnico a la cultura, para ciertos autores como Peter Wade, no existen diferencias desde la academia entre ambas categorías: ambas son construcciones sociales, son contextuales, situacionales y polisémicas (Wade,1997).

En resumen, las ideas raciales son sobre la diferencia física humana de varios tipos; se refieren típicamente, pero no exclusivamente, a categorías históricas clave de origen colonial, y producen explicaciones naturalizantes de la cultura [Wade, 2008].

Las estadísticas nacionales en América Latina muestran variaciones en los montos de población autoadscrita como indígena que son inexplicables desde la teoría culturalista. Tal es el caso de México, en el que la proporción 
de población autoadscrita a una cultura indígena se elevó de $14.9 \%$ en 2010 a $21.5 \%$ en 2015 en la población de cinco años y más, esta vez sin cambios en el fraseo de las preguntas. Sería muy difícil pensar que factores culturales fueran la causa de un incremento en 6.6 puntos porcentuales de la población indígena en el lapso de cinco años, puesto que precisamente estos factores son usados para explicar la permanencia de la identidad indígena y no su cambio súbito.

Otro golpe reciente al culturalismo lo constituye lo que se ha denominado la pigmentocracia, que entre otras cosas ha demostrado fehacientemente, gracias al uso de la paleta de colores, la fuerte correlación estadística existente en América Latina entre el color de piel y la escolaridad (Telles, 2014), lo que sitúa a lo étnico-racial más en el campo de la desigualdad social y la opresión, que en el campo de lo cultural.

Todo esto apunta a que en estos momentos se están dando las condiciones para el surgimiento de un giro diametral de la percepción de la identidad étnica en nuestro país, que va desde un enfoque culturalista de la identidad indígena -en el que los indígenas parecieran inamovibles, provenientes de un pasado precolombino-, propio de una realidad esencialista, hasta la visión posmoderna de las identidades, donde existe un número casi infinito de ellas, todas coexisten y tienen el mismo valor y la misma importancia, cada vez más en la esfera de lo efímero y del individualismo, como un fenómeno ante todo subjetivo, mucho más moldeable y plástico, como un recurso que se moviliza y que es de difícil definición y medición. Tal vez esta nueva percepción sea necesaria para el surgimiento de un estado verdaderamente pluricultural.

Sirvan las líneas anteriores para enfatizar que, en la actualidad, la búsqueda de comportamientos específicos que pudieran ser atribuidos a una cultura indígena pareciera desaconsejar el uso de la categoría totalizadora de "indígena" por ser demasiado aglutinadora de realidades colectivas disímiles. En cambio, pareciera mejor recurrir a grupos específicos con culturas concretas, en contextos territoriales delimitados.

Para los demógrafos, quienes trabajamos con estadísticas, un impedimento para identificar a los grupos étnicos ha sido que, si bien se cuenta con una categoría censal bastante desagregada y aceptada de grupos etnolingüísticos, en las estadísticas no está disponible una variable territorial oficial o aceptada para poder delimitarlos apropiadamente como grupos étnicos. Es decir, sabemos por las encuestas ampliadas de los censos de 2000, 2010 y la encuesta intercensal de 2015, en qué municipio reside cada uno de los hablantes del náhuatl incluidos en la muestra, pero no sabemos cómo agruparlos por municipios para identificarlos por comunidades. 
Curiosamente, la Comisión Nacional para el Desarrollo de los Pueblos Indígenas (CDI) y el Programa de Naciones Unidas para el Desarrollo (PNUD) publicaron en 2006 un trabajo en el que delimitan las 25 principales regiones indígenas de México (CDI-PNUD, 2006). Estos resultados, además de ser oficiales, presentan con cierto grado de claridad metodológica el procedimiento seguido para la demarcación de las regiones, lo que lo ubica como el ejercicio más consistente y verificable, entre los pocos existentes en su tipo en el país hasta ahora. ¿Por qué su uso no se ha propagado? Por alguna extraña razón, la publicación referida no ofrece el listado, ya no digamos de las claves, de los nombres de los municipios de cada una de las 25 regiones; únicamente los presenta en mapas, lo que representa un grave obstáculo para su uso en bases de datos nacionales. Es por ello que, en el presente trabajo, se utiliza una transcripción hecha ex profeso de los resultados de las regiones indígenas publicadas por la CDI-PNUD (2006) como herramienta para demarcar a los grupos etnolingüísticos por regiones indígenas, y de esta forma obtener categorías similares a los grupos étnicos.

Los objetivos del presente artículo son, por un lado, mostrar la variedad de niveles de fecundidad indígena a la escala más desagregada posible, y por otro, validar la hipótesis que considera a la etnia como un determinante de la fecundidad en México.

\section{Metodología}

Las bases de datos empleadas en este trabajo fueron obtenidas del cuestionario ampliado del Censo de Población y Vivienda del año 2000 y de la Encuesta Intercensal del año 2015, ambos del INEGI.

Para identificar las regiones indígenas, este estudio se basó en el libro Las regiones indígenas de México, publicado por la CDI-PNUD en 2006. En dicha obra se detalla la metodología empleada, la cual se resume a continuación. La unidad político-administrativa más pequeña empleada para esta regionalización fue el municipio. La CDI consideró a la población indígena bajo el criterio etnolingüístico, por tanto, contempla a los habitantes de hogares en donde el jefe, el cónyuge o sus ascendientes (padre, madre, abuelos) han declarado ser hablantes de lengua indígena. Primordialmente se identificó y seleccionó a los municipios con $40 \%$ y más de población indígena. A esta primera selección se le agregaron municipios que superaran el $10 \%$ de población indígena y finalmente algunos otros municipios con menos de $10 \%$ de población indígena que contuvieran poblaciones indígenas minoritarias. 
La metodología empleada para la selección de los municipios consistió en aplicar tres tipos de criterios: a) históricos, económicos y lingüísticos; b) contigüidad geográfica; y c) inclusión de la población dispersa. Con base en dichos criterios, se buscó identificar los espacios indígenas tradicionales; es decir, los lugares ocupados históricamente por pueblos prehispánicos y donde han permanecido, y que comparten además características lingüísticas y culturales, cultos, cosmovisiones y relaciones de parentesco. En el aspecto económico se consideraron aspectos como: rutas comerciales establecidas históricamente, centros de desarrollo dentro de las zonas indígenas o bien que pueden incluirse en las mismas, así como zonas enclavadas. Otro factor significativo fue la continuidad, que incluye la contigüidad vecinal de límites municipales, así como las características morfológicas y las posibilidades de comunicación interregional. Por último, si bien el paso inicial fue la selección de los municipios, finalmente se recurrió a seleccionar las localidades con población indígena que permitieran representar a los municipios con población indígena dispersa y a los municipios fraccionados; en ambos casos se corroboró que fueran contiguos, bien comunicados e histórica, económica y lingüísticamente compatibles con la región contigua. Para profundizar en la metodología, se recomienda consultar la obra referida (CDI-PNUD, 2006).

En el presente trabajo, la delimitación de las 25 regiones indígenas originales de la CDI fue replicada a partir de los 886 municipios completos; es decir, aquellos que cumplieron con los criterios metodológicos que se reseñaron en líneas anteriores, y se excluyeron los municipios "fraccionados", esto es, los segmentos de municipios sobre los cuales se concentran varias localidades indígenas en un municipio no indígena.

Con la finalidad de identificar los grupos étnicos específicos que pudieran vivir en comunidad y compartir condiciones sociales, económicas, culturales e históricas comunes y diferentes a las del resto, se procedió a identificar a los grupos étnicos a la escala más reducida posible. Para ello se seleccionó a la población por lengua indígena (las 70 lenguas del catálogo del Instituto Nacional de Lenguas Indígenas, INALI, de 2015) según su localización dentro de las 25 regiones indígenas de la CDI. Para los grupos resultantes se estimó la tasa global de fecundidad (TGF) y se descartaron del análisis descriptivo aquéllos con efectivos insuficientes para dicho propósito. De esta forma, se identificaron 85 subpoblaciones indígenas de 23 regiones para el año 2015, menos las regiones Chimalapas y Frontera Sur por su escasez de efectivos. De este modo, en el presente artículo denominamos grupos étnicos a los grupos etnolingüísticos que residen en alguna de las regiones indígenas, y simplemente como grupos etnolingüísticos a aquellos que residen en cualquier parte del territorio nacional pero fuera de las regio- 
nes indígenas. Para evitar confusiones, cabe aclarar que tanto los grupos étnicos como los etnolingüísticos son grupos etnolingüísticos, con la única diferencia de que los primeros residen en una o más de las regiones indígenas, y los segundos habitan fuera de ellas, en el resto del territorio nacional, sin distinguir en qué municipios (en las ciudades o en el campo, agrupados o desagrupados) (véase el Esquema 1).

Pese al gran tamaño de la muestra, pudieron estimarse las TGF para 39 lenguas de las 70 existentes. Por su reducido número de efectivos, quedaron fuera del estudio las siguientes 30 lenguas: 1. kickapoo, 2. pápago, 3. pima, 4. guarijío, 5. paipai, 6. cucapá, 7. kumiai, 8. kiliwa, 9. seri, 10. tlahuica, 11. ixcateco, 12. chocholteco, 13. lacandón, 14. q'anjob'al, 15. akateko, 16. jakalteko, 17. qato'k, 18. chuj, 19. q'eqchi', 20. k'iche', 21. kaqchikel, 22. teko, 23. awakateko, 24. ixil, 25. sayulteco, 26. oluteco, 27. ayapaneco, 28. chontal insuficientemente especificado, 29. tepehuano insuficientemente especificado, 30. popoluca insuficientemente especificado.

\section{Esquema 1}

Categorías indígenas

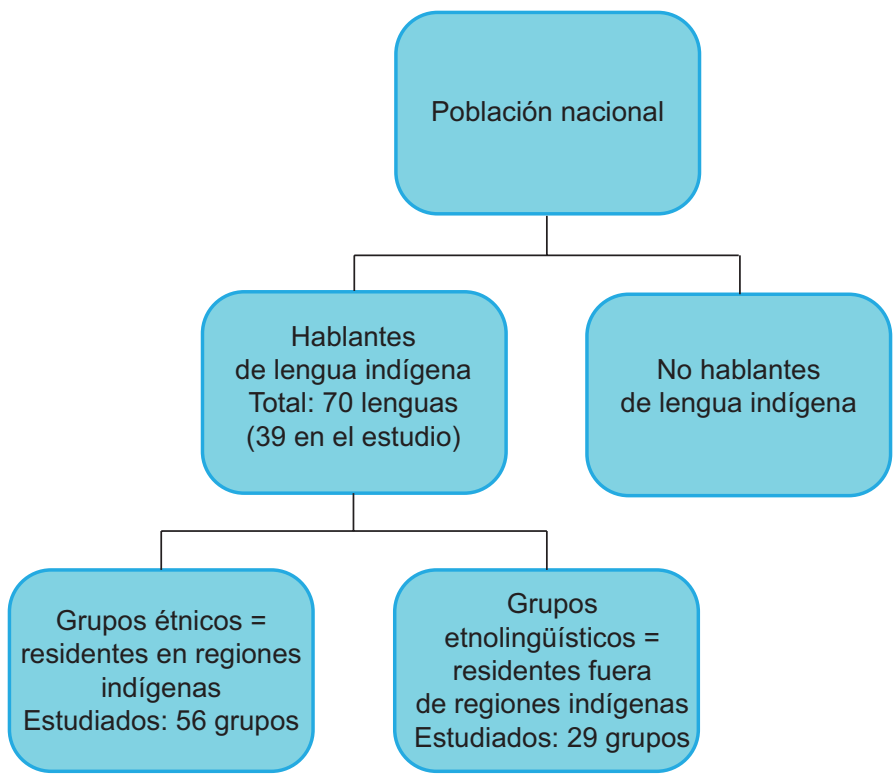

Fuente: Elaboración propia. 


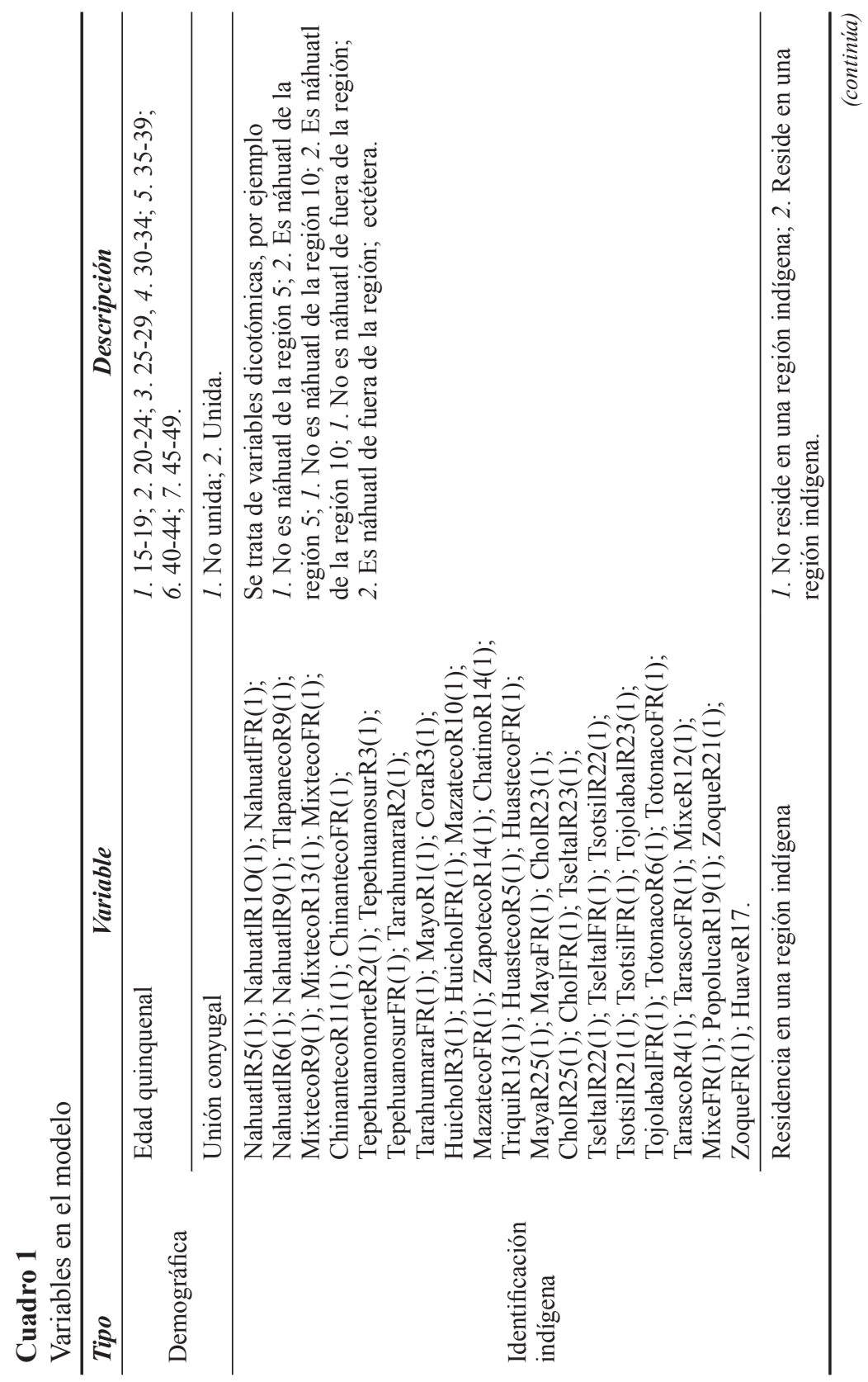




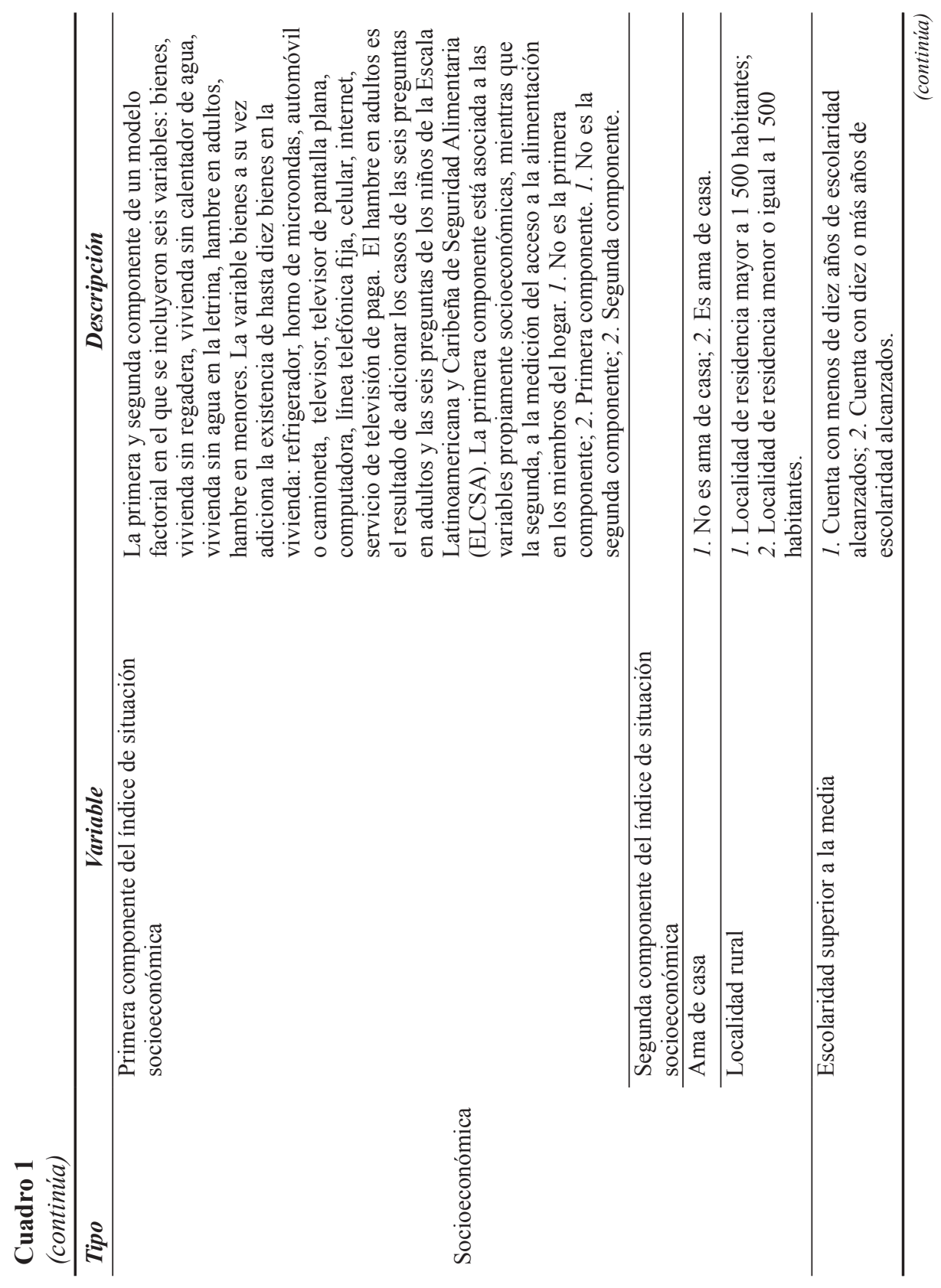




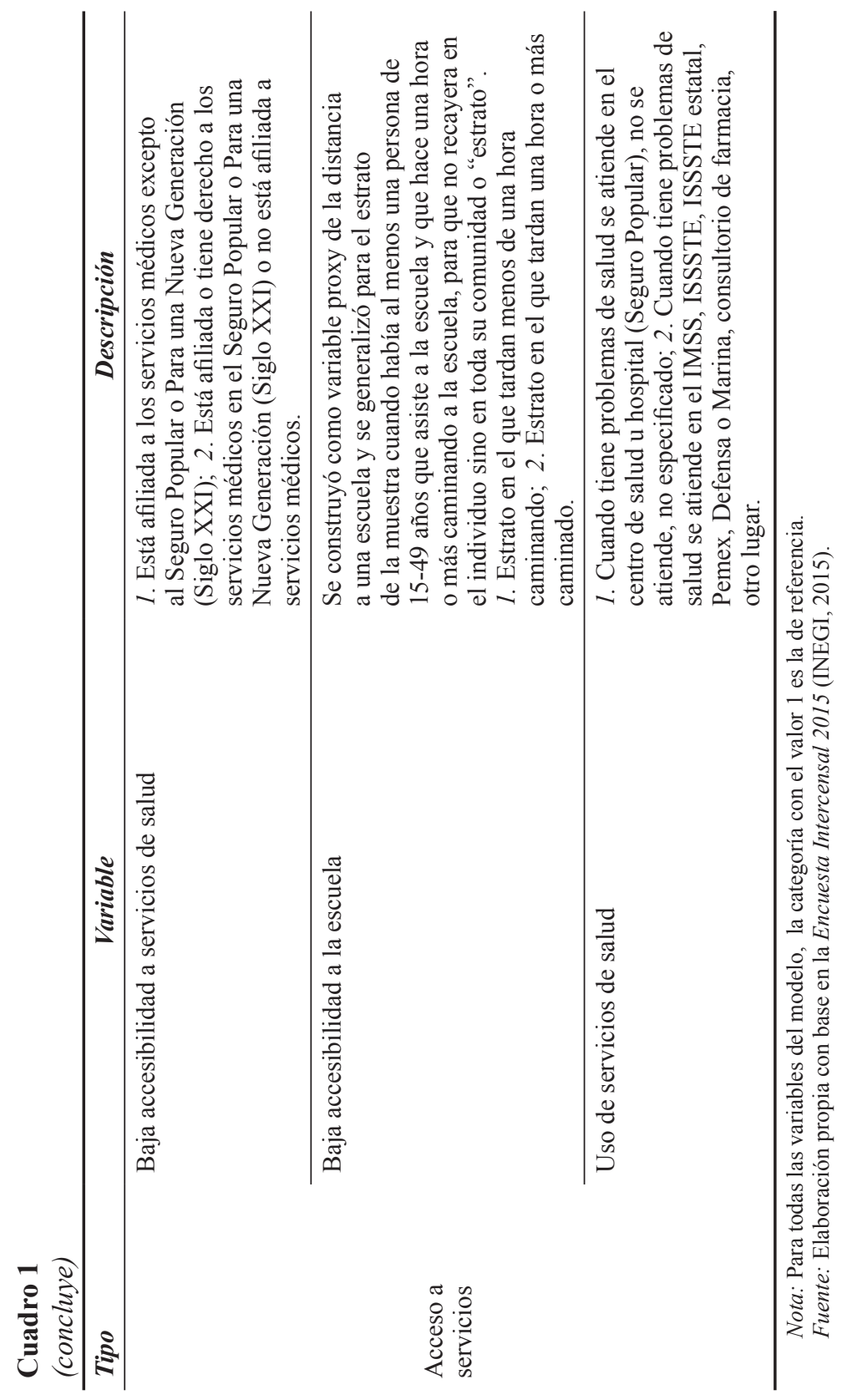


La estimación de las tasas de fecundidad para los años 1999 y 2014 y sus intervalos de confianza al 95\% fueron realizadas con base en modelos Poisson, tal como lo propone Schoumaker (2004). Como regla general, se adoptó el criterio de excluir del análisis descriptivo las TGF en las que la amplitud del intervalo de confianza fuera mayor o igual a la propia TGF.

Con el objeto de probar si los grupos étnicos y etnolingüísticos tienen una influencia específica sobre la probabilidad de ocurrencia de un nacimiento durante el año 2014 (variable dependiente), se incluyeron las 85 variables explicativas (56 grupos étnicos y 29 grupos etnolingüísticos) en un modelo logístico, junto con 13 variables de distintos tipos: demográficas, de identificación indígena, socioeconómicas y acceso a servicios (véase el Cuadro 1).

\section{Resultados}

\section{Fecundidad en las regiones indígenas tradicionales}

Los niveles de fecundidad observados en el conjunto de las regiones indígenas (véase el Mapa 1) decrecieron durante el periodo 1999-2014 y su descenso es mayor que el de la fecundidad del resto del país, lo cual los está llevando a la convergencia. La tasa global de fecundidad para el total de las regiones indígenas pasó de 3.4 a 2.5 hijos por mujer en los años 1999 y 2014 , respectivamente, mientras que para el resto del país los valores fueron de 2.7 a 2.1 hijos por mujer, lo cual hace una diferencia de 0.7 hijos en 1999 y 0.4 hijos en 2014 más en las TGF de las regiones indígenas que en el resto del país (véase el Cuadro 2).

La convergencia de los niveles de la fecundidad en las regiones indígenas y el resto de la nación se verifica igualmente para el mismo periodo al considerar otro agregado panétnico, como es la categoría de hablantes de lengua indígena (HLI) y no hablantes de lengua indígena (NoHLI) a escala nacional (Vázquez y Cenobio, 2017).

Esta convergencia podría o no estar acompañada de pérdida de la variabilidad de niveles de fecundidad entre grupos étnicos, lo cual a su vez podría ser resultado de la estandarización de los comportamientos reproductivos. En el caso de las regiones indígenas, sí se observa una reducción de la dispersión. Para corroborarlo se calculó la varianza $\left(s^{2}=\frac{\sum_{i}^{n}\left(y_{i}-\bar{y}\right)^{2}}{n-1}\right)$ de las TGF de las 24 regiones de las que se tienen datos con base en los valores del Cuadro 2, considerando como media el valor de la TGF para el conjunto de las regiones indígenas, tanto para 1999 como para 2014, y se obtuvieron los 


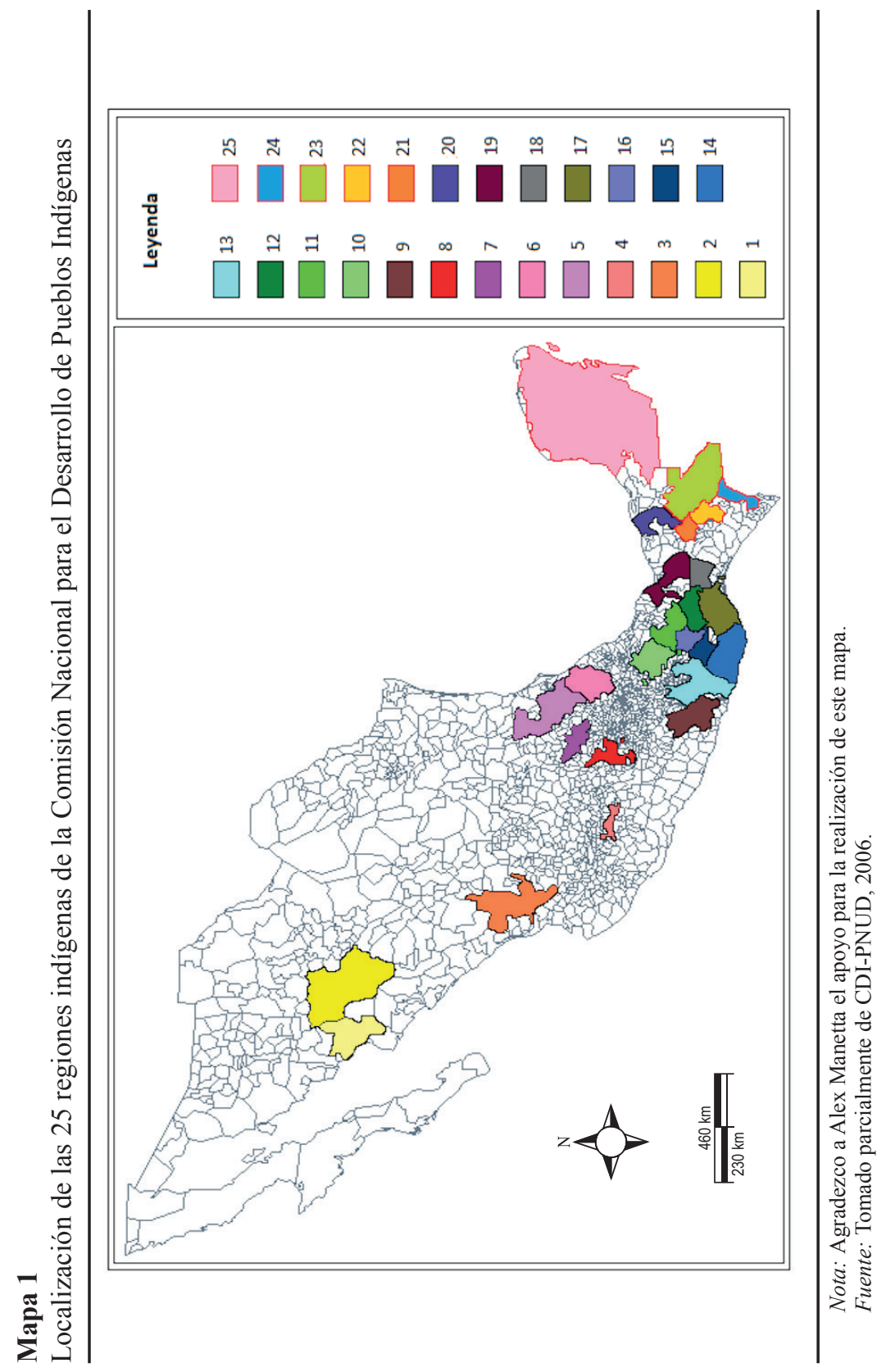




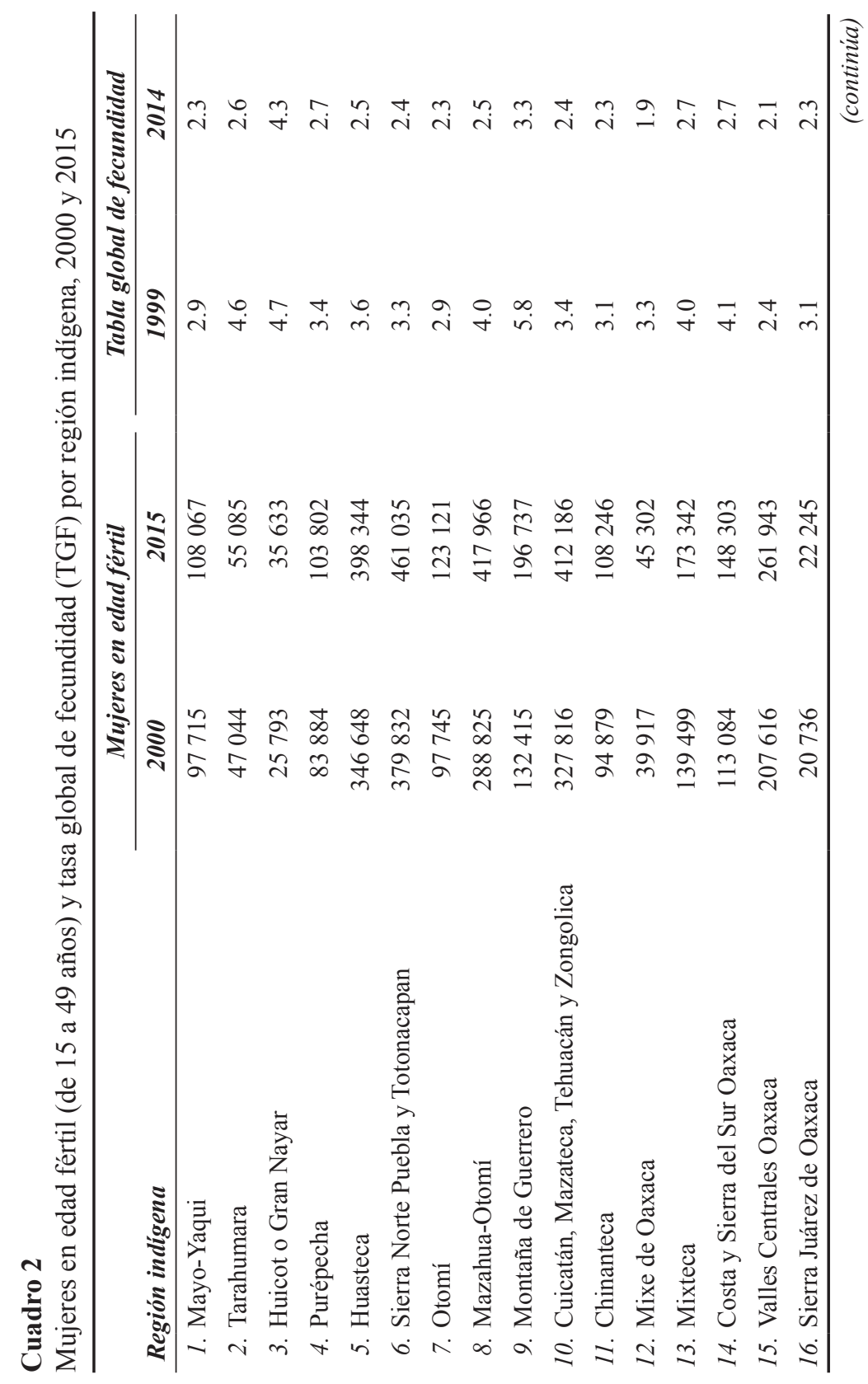




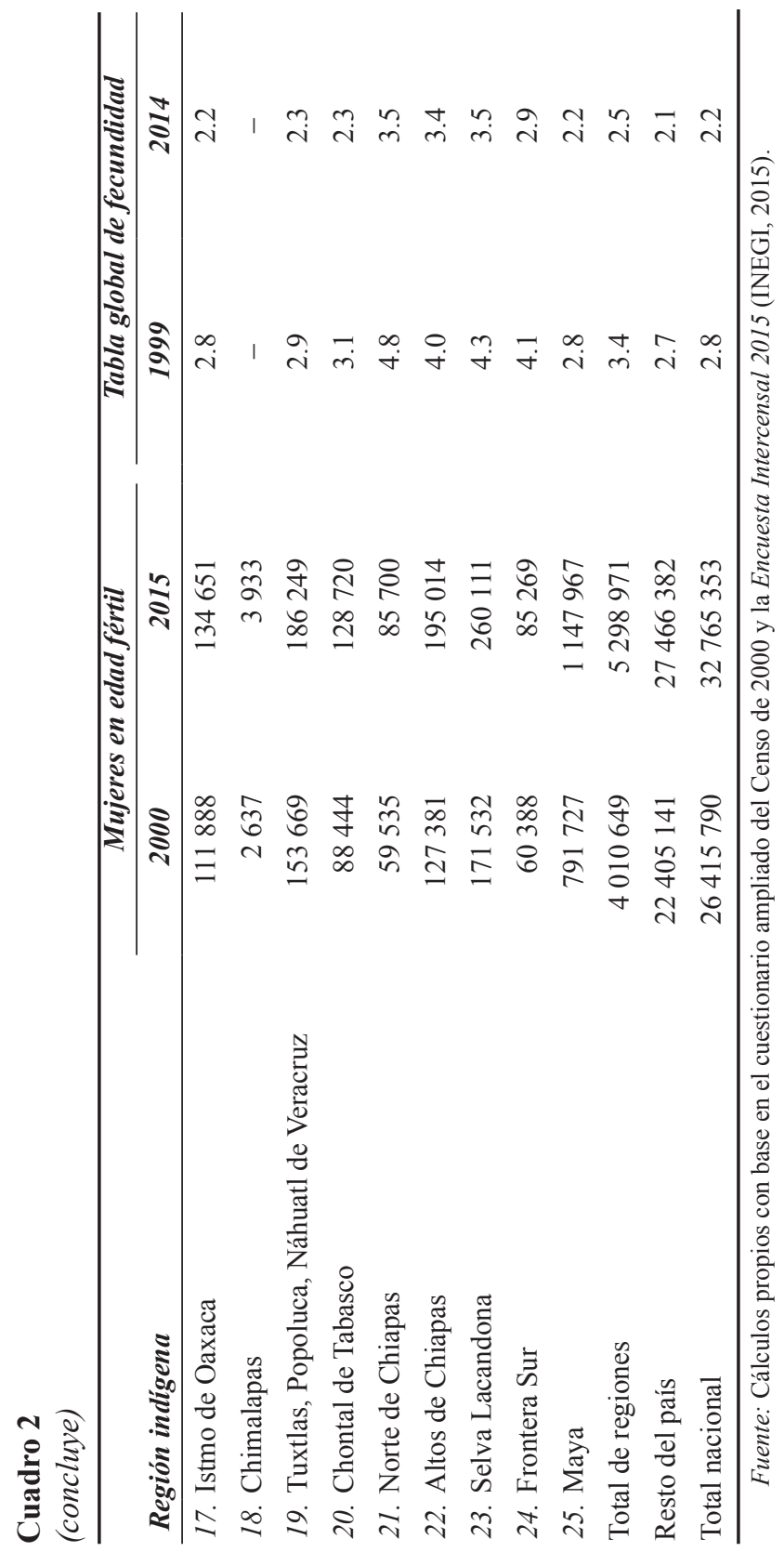


siguientes valores: $s_{1999}^{2}=14.1$ y $s_{2014}^{2}=7.4$. Por lo anterior, es de esperar que la singularidad de los comportamientos reproductivos en las regiones indígenas haya desaparecido en parte durante el periodo de referencia.

En 1999 se observa una fuerte variabilidad de los niveles de fecundidad entre las 24 regiones indígenas en las que se cuenta con la TGF. El nivel más alto lo presentó la Montaña de Guerrero, con 5.8 hijos por mujer, más del doble de la tasa nacional de ese año. Otras regiones de muy alta fecundidad eran las del Norte de Chiapas (4.8 hijos por mujer), Huicot o Gran Nayar (4.7 hijos por mujer) y Tarahumara (4.6 hijos por mujer). La tasa menor se presentó en la región Valles Centrales de Oaxaca, con 2.4 hijos por mujer, menor aún al promedio nacional, que fue de 2.8 hijos por mujer. Hubo cinco regiones con niveles iguales o superiores por 0.1 hijos por mujer a la TGF nacional: Maya; Tuxtlas, Popoluca, Náhuatl de Veracruz; Istmo de Oaxaca; Otomí; y Mayo-Yaqui.

En el año 2014, la región que presenta el nivel más elevado de fecundidad es la Huicot o Gran Nayar, con una TGF de 4.3 hijos por mujer, lo que representa un poco menos del doble de la fecundidad a nivel nacional. Le siguen la Selva Lacandona; el Norte de Chiapas (ambos con 3.5 hijos por mujer); Altos de Chiapas (3.4 hijos por mujer); y Montaña de Guerrero (3.3 hijos por mujer). En esta ocasión hubo dos regiones con niveles inferiores al promedio nacional: Mixe de Oaxaca, con una TGF de 1.9 hijos por mujer, la cual es menor al nivel nacional de ese año -que fue de 2.2 hijos por mujer-y menor al nivel de reemplazo - que es de 2.1 hijos por mujer-; y nuevamente Valles Centrales de Oaxaca (2.1 hijos por mujer). Se contabilizaron ocho regiones con niveles iguales o superiores por 0.1 hijos por mujer al promedio nacional: Maya; Chontal de Tabasco; Tuxtlas, Popoluca, Náhuatl de Veracruz; Istmo de Oaxaca; Sierra Juárez de Oaxaca; Chinanteca; Otomí; y Mayo-Yaqui.

Es muy variable el tamaño poblacional de las regiones indígenas, como se infiere porque el número de mujeres en edad fértil en la región de Chimalapa es 300 veces menor al de la región Maya. En su conjunto, las mujeres en edad fértil de las regiones indígenas del país, que representan el 16\% del total nacional, aportaron $19 \%$ de los nacimientos nacionales.

El descenso de la TGF durante los 15 años que transcurrieron entre 1999 y 2014, para el conjunto de las regiones indígenas, fue de $26 \%$ respecto a los valores de 1999 , superior al $22 \%$ observado en el país. Todas las regiones indígenas presentaron un descenso de la fecundidad, pero en magnitudes y proporciones muy dispares.

Las dos regiones con un decremento más significativo en términos absolutos son la Montaña de Guerrero y la Tarahumara, con un descenso de 2.5 y 2.0 hijos por mujer, respectivamente. Estas regiones también fueron en 
las que esta caída representó un cambio mayor respecto al valor de 1999: $43 \%$ en ambos casos. Le sigue la región Mixe de Oaxaca, con un descenso del $42 \%$ respecto al nivel de 1999. En este último caso, la región alcanzó un nivel notablemente bajo de fecundidad para el contexto indígena: 1.9 hijos por mujer.

Las regiones que presentaron un muy bajo descenso proporcional de la fecundidad fueron la Huicot o Gran Nayar, con 8\%; Valles Centrales de Oaxaca, con 14\%; y Altos de Chiapas, con 15 por ciento.

\section{La fecundidad de los grupos étnicos en 2014}

Para la estimación de las TGF en el año 2014, fue posible desagregar 56 grupos étnicos al separar a la población de las 25 regiones por grupos etnolingüísticos. También se pudo estimar la TGF para 27 grupos etnolingüísticos. Con base en los resultados de la encuesta intercensal de 2015, cabe mencionar que $81 \%$ de la población de ambos sexos de tres años y más que hablaba alguna lengua indígena residía en las 25 regiones aludidas.

En el estudio de la fecundidad por grupo étnico, es importante considerar que una minoría de grupos etnolingüísticos, sobre todo los demográficamente más grandes, están presentes en varias regiones indígenas formando grupos étnicos diferentes. Por esta razón, es de esperar que el grupo etnolingüístico tenga comportamientos reproductivos distintos dependiendo de la región en la que se encuentra. Estos son los náhuatl y zapotecos, presentes en cinco regiones cada uno; los otomíes, que están en cuatro regiones; los mixes, ch'oles y mixtecos, presentes en tres regiones cada uno; los chinantecos, mazatecos, amuzgos, tzeltales, tzotziles y totonacos, en dos regiones cada uno.

Asimismo, la mayoría de las regiones son pluriculturales, es decir contienen a varias etnias indígenas, por lo que dentro de estas regiones sería de esperar encontrar comportamientos reproductivos distintos en función de las culturas que las componen. En 18 regiones están presentes más de un grupo etnolingüístico, excepto en las regiones Mayo-Yaqui, Purépecha, Otomí, Mixe de Oaxaca, Sierra Juárez de Oaxaca, Chimalapas y Frontera Sur. En el interior de estas regiones pluriculturales fue posible identificar 12 grupos etnolingüísticos repetidos, sin embargo, existen muchos más grupos etnolingüísticos que residen en una sola región indígena; en total se pudo estimar la TGF de 23 de ellos. De este modo, una región cuenta con cinco grupos etnolingüísticos distintos (la región 5); cuatro regiones con cuatro grupos $(9,10,11$ y 17); seis con tres grupos $(3,6,13,15,19$ y 23$)$; siete con dos 
$(2,8,14,20,21,22$ y 25$)$; cinco con uno $(1,4,7,12$ y 16$)$, y dos con cero (18 y 24), que, como ya se mencionó, su reducido número de efectivos impidió la estimación de la TGF por grupo étnico.

En tanto que la región y el grupo etnolingüístico aportan variabilidad al fenómeno de la fecundidad, es muy válido preguntarse cuál de los dos factores aporta más variabilidad. Para responder a esta pregunta se estimó el rango de variación promedio entre las TGF de las etnias y las regiones para el año 2014. ${ }^{1}$ Se encontró un poco más de variabilidad de las TGF entre las distintas regiones por cada lengua que entre las diferentes lenguas por cada región ( 0.73 y 0.67 hijos promedio por mujer, respectivamente). De lo anterior, se puede inferir que pesa más como influencia sobre la fecundidad la región que la lengua, al menos considerando el universo de las regiones indígenas.

Por lo que toca a los niveles de la fecundidad, las 56 etnias estudiadas en 2014 presentan un rango de variación de 3.6 hijos por mujer entre el valor más bajo, de 2.0 hijos por mujer de los mayos de la región Mayo-Yaqui, y el valor más alto de 5.6 hijos por mujer de los coras de la región Huicot o Gran Nayar (véase el Cuadro 2).

A título de parámetro a escala mundial, la fecundidad de los coras de la Huicot es similar a la de Burkina Faso (5.6 hijos por mujer en 2010-2015), mientras que la de los mayos de la región Mayo-Yaqui es idéntica a la de Francia (2.0 hijos por mujer en 2010-2015) (United Nations, 2015).

Otros datos que permiten valorar la amplitud del intervalo interétnico de 3.6 hijos por mujer emanan de revisar los niveles de la fecundidad asociados a algunos de los determinantes contextuales de la fecundidad para México en 2014: las mujeres analfabetas tienen una TGF de 2.7 hijos por mujer, mientras que las alfabetas 2.2 , variando sólo en 0.5 hijos por mujer; las que tienen 0 años de escolaridad acumulada tienen 2.6 hijos por mujer, mientras que las que acumulan 14 años tienen 1.5 hijos por mujer, y la variación es de 1.1 hijos por mujer; las que se dedican a los quehaceres del hogar presentan una TGF de 3.9 hijos por mujer, mientras que las no lo hacen tienen 1.2 hijos por mujer, lo cual produce una diferencia de 2.7 hijos por

1 Se estimó de la siguiente forma: 1) Rango promedio de variación de las lenguas por región: $\sum_{i=1}^{n} \frac{S_{i j}-I_{i j}}{n}$ donde: $S_{i}=$ valor superior del grupo etnolingüístico $i$ presente en las distintas regiones $j ; I_{i}=$ valor inferior del grupo etnolingüístico $i$ presente en las distintas regiones j; $n=$ número de grupos etnolingüísticos. 2) Rango promedio de variación de las regiones por lengua: $\sum_{j=1}^{n} \frac{S_{i j}-I_{i j}}{n}$ donde: $S_{i}=$ valor superior del grupo etnolingüístico $i$ dentro de la región $j ; I_{i}=$ valor inferior del grupo etnolingüístico $i$ dentro de la región $j ; n=$ número de regiones.

Estudios Demográficos y Urbanos, vol. 34, núm. 3 (102), 2019, pp. 497-534 doi: http://dx.doi.org/10.24201/edu.v34i3.1850 
mujer; y las que residen en una localidad menor de 2500 habitantes tienen 2.7 hijos por mujer, mientras que las residentes en localidades de $100000 \mathrm{o}$ más habitantes tienen una TGF de 1.9 hijos por mujer, con una diferencia de apenas 0.8 hijos por mujer.

La TGF de las 53 etnias en su conjunto es de 3.1 hijos por mujer en 2014; 19 etnias presentan valores mayores a la media y 34 valores menores. Los tres grupos étnicos con mayor fecundidad pertenecen a la región Huicot o Gran Nayar: coras, tepehuanos del sur y huicholes. Compartiendo el tercer lugar se encuentran los tepehuanos del norte de la región Tarahumara. Con los valores más bajos, de 2.0 hijos por mujer, lo cual está por debajo del nivel de reemplazo, se ubican los mayos de la región Mayo-Yaqui y los nahuas de la región Tuxtlas, Popoluca, Náhuatl de Veracruz. En el nivel de reemplazo (2.1 hijos por mujer) están los cuicatecos de la región Cuicatán, Mazateca, Tehuacán, Zongolica (véase el Cuadro 3).

Los 27 grupos etnolingüísticos presentan una TGF promedio menor a los grupos étnicos: 2.8 hijos por mujer. El valor más alto es de 3.8 hijos por mujer de los tzeltales y el más bajo de 1.7 hijos por mujer de los mixes (véase el Cuadro 4).

\section{Comparación de la fecundidad de los grupos étnicos en 1999 y 2014}

La estimación del cambio de los niveles de la fecundidad durante el periodo estudiado, 1999-2014, se redujo a los 31 grupos étnicos en los cuales existían diferencias en la fecundidad, y éstas fueron lo suficientemente significativas estadísticamente para que no se traslaparan los intervalos de confianza de la TGF de un año con el otro (Gráfica 1).

Existen grupos étnicos que han reducido muy notablemente su nivel de fecundidad, como es el caso de los amuzgos de la Montaña de Guerrero, quienes la redujeron en $165 \%$, pasando de 6.6 a 2.5 hijos por mujer; los choles de la región Chontal de Tabasco la redujeron en 115\%, al pasar de 5.5 a 2.5 hijos por mujer; los cuicatecos de la región Cuicatlán, Mazateca, Tehuacán y Zongolica en 113\%, al pasar de 4.6 a 2.1 hijos por mujer; los mayos de la región Mayo-Yaqui en 107\%, al pasar de 4.1 a 2.1 hijos por mujer; los otomíes de la región Mazahua-Otomí en 88\%, al pasar de 5.2 a 2.8 hijos por mujer; y los tlapanecos de la Montaña de Guerrero en $87 \%$, pasando de 6.5 a 3.5 hijos por mujer.

Si en lugar de analizar el valor medio, se considera la estimación más conservadora, es decir aquella basada en la diferencia entre el mínimo valor en 1999 y el máximo en 2014 dentro de los intervalos de confianza de la TGF, 


\section{Cuadro 3}

Tasa global de fecundidad por grupo étnico 2014 y límites inferior y superior de los intervalos de confianza al $95 \%$

\begin{tabular}{|c|c|c|c|}
\hline Etnia & $\begin{array}{l}T G F \\
2014\end{array}$ & L.I. & L.S. \\
\hline Mayo de la región Mayo-Yaqui & 2.0 & 1.5 & 2.7 \\
\hline $\begin{array}{l}\text { Náhuatl de la región Tuxtlas, Popoluca, } \\
\text { Náhuatl Veracruz }\end{array}$ & 2.0 & 1.7 & 2.4 \\
\hline $\begin{array}{l}\text { Cuicateco de la región Cuicatán, Mazateca, } \\
\text { Tehuacán, Zongolica }\end{array}$ & 2.1 & 1.5 & 3.1 \\
\hline Otomí de la región Huasteca & 2.3 & 2.0 & 2.6 \\
\hline $\begin{array}{l}\text { Otomí de la región Sierra Norte Puebla } \\
\text { y Totonacapan }\end{array}$ & 2.3 & 1.9 & 2.8 \\
\hline Otomí de la región Otomí & 2.3 & 1.7 & 3.3 \\
\hline Zapoteco de la región Valles Centrales Oaxaca & 2.3 & 2.1 & 2.6 \\
\hline Zapoteco de la región Istmo Oaxaca & 2.3 & 2.1 & 2.6 \\
\hline Zapoteco de la región Sierra Juárez Oaxaca & 2.4 & 2.0 & 2.8 \\
\hline Zapoteco de la región Chinanteca & 2.5 & 1.7 & 3.6 \\
\hline Mixe de la región Mixe Oaxaca & 2.5 & 2.2 & 2.8 \\
\hline Mixteco de la región Valles Centrales Oaxaca & 2.5 & 1.9 & 3.5 \\
\hline Mixe de la región Valles Centrales Oaxaca & 2.5 & 1.9 & 3.3 \\
\hline Chol de la región Chontal de Tabasco & 2.5 & 2.0 & 3.3 \\
\hline Maya de la región Maya & 2.5 & 2.4 & 2.6 \\
\hline Amuzgo de la región Montaña de Guerrero & 2.5 & 2.0 & 3.1 \\
\hline Totonaco de la región Huasteca & 2.6 & 2.5 & 2.8 \\
\hline Náhuatl de la región Huasteca & 2.7 & 2.6 & 2.8 \\
\hline $\begin{array}{l}\text { Náhuatl de la región Sierra Norte Puebla } \\
\text { y Totonacapan }\end{array}$ & 2.7 & 2.5 & 2.9 \\
\hline $\begin{array}{l}\text { Mazateco de la región Cuicatán, Mazateca, } \\
\text { Tehuacán, Zongolica }\end{array}$ & 2.7 & 2.5 & 2.9 \\
\hline Chontal de Tabasco de la región Chontal de Tabasco & 2.7 & 2.1 & 3.5 \\
\hline Tarasco de la región Purépecha & 2.8 & 2.5 & 3.1 \\
\hline Huasteco de la región Huasteca & 2.8 & 2.5 & 3.0 \\
\hline Mazahua de la región Mazahua-Otomí & 2.8 & 2.5 & 3.1 \\
\hline Otomí de la región Mazahua-Otomí & 2.8 & 2.4 & 3.2 \\
\hline Chinanteco de la región Chinanteca & 2.8 & 2.5 & 3.1 \\
\hline Mixteco de la región Mixteca & 2.8 & 2.7 & 3.0 \\
\hline Amuzgo de la región Mixteca & 2.8 & 1.9 & 4.2 \\
\hline
\end{tabular}




\section{Cuadro 3}

(concluye)

\begin{tabular}{lccc}
\hline Etnia & TGF & & \\
\hline Tepehua de la región Huasteca & $\mathbf{2 0 1 4}$ & L.I. & L.S. \\
Náhuatl de la región Cuicatán, Mazateca, Tehuacán, & 2.9 & 2.1 & 4.2 \\
$\quad$ Zongolica & 2.9 & 2.7 & 3.0 \\
Popoluca de la región Tuxtlas, Popoluca, & & & \\
$\quad$ Náhuatl Veracruz & 2.9 & 2.5 & 3.4 \\
Chatino de la región Costa y Sierra del Sur Oaxaca & 3.0 & 2.7 & 3.5 \\
Huave de la región Istmo Oaxaca & 3.0 & 2.4 & 3.8 \\
Conjunto de las 53 etnias & 3.1 & - & - \\
Chol de la región Maya & 3.0 & 2.5 & 3.6 \\
Tojolabal de la región Selva Lacandona & 3.1 & 2.7 & 3.6 \\
Mazateco de la región Chinanteca & 3.3 & 2.5 & 4.2 \\
Zapoteco de la región Costa y Sierra del Sur Oaxaca & 3.3 & 3.0 & 3.6 \\
Chinanteco de la región Tuxtlas, Popoluca, & & & \\
$\quad$ Náhuatl Veracruz & 3.3 & 2.3 & 4.7 \\
Tarahumara de la región Tarahumara & 3.4 & 3.0 & 3.9 \\
Tlapaneco de la región Montaña de Guerrero & 3.5 & 3.2 & 3.8 \\
Náhuatl de la región Montaña de Guerrero & 3.6 & 3.3 & 3.9 \\
Triqui de la región Mixteca & 3.6 & 2.9 & 4.5 \\
Chol de la región Selva Lacandona & 3.7 & 3.5 & 4.0 \\
Mixteco de la región Montaña de Guerrero & 3.9 & 3.6 & 4.2 \\
Zoque de la región Norte de Chiapas & 3.9 & 3.4 & 4.4 \\
Tzotzil de la región Altos de Chiapas & 3.9 & 3.7 & 4.1 \\
Tzotzil de la región Norte de Chiapas & 4.2 & 3.9 & 4.6 \\
Tzeltal de la región Selva Lacandona & 4.2 & 4.0 & 4.4 \\
Tzeltal de la región Altos de Chiapas & 4.3 & 4.0 & 4.6 \\
Tepehuano del norte de la región Tarahumara & 4.8 & 3.7 & 6.3 \\
Huichol de la región Huicot o Gran Nayar & 4.8 & 4.1 & 5.5 \\
Tepehuano del sur de la región Huicot o Gran Nayar & 5.2 & 4.5 & 6.1 \\
Cora de la región Huicot o Gran Nayar & 5.6 & 4.8 & 6.6 \\
\hline$\quad$ Nota TGF: & & \\
\hline
\end{tabular}

Nota: TGF: tasa global de fecundidad; L.I.: límite inferior; L.S.: límite superior. Fuente: Cálculos propios con base en la Encuesta Intercensal 2015 (INEGI, 2015). 


\section{Cuadro 4}

Tasa global de fecundidad por grupo etnolingüístico fuera de las regiones indígenas y límites inferior y superior de los intervalos de confianza al 95\%

\begin{tabular}{|c|c|c|c|}
\hline Grupo & TGF 2014 & L.I. & L.S. \\
\hline Mixe & 1.7 & 1.3 & 2.2 \\
\hline Cora & 2.4 & 1.6 & 3.7 \\
\hline Chol & 2.4 & 1.9 & 3.0 \\
\hline Otomí & 2.4 & 2.1 & 2.7 \\
\hline Mazahua & 2.4 & 2.0 & 2.9 \\
\hline Zapoteco & 2.5 & 2.2 & 2.9 \\
\hline Pame & 2.5 & 1.9 & 3.5 \\
\hline Amuzgo & 2.5 & 2.1 & 3.1 \\
\hline Náhuatl & 2.6 & 2.5 & 2.7 \\
\hline Mayo & 2.6 & 2.0 & 3.4 \\
\hline Tlapaneco & 2.6 & 2.1 & 3.2 \\
\hline Chontal de Tabasco & 2.7 & 2.0 & 3.7 \\
\hline Tarasco & 2.8 & 2.5 & 3.2 \\
\hline Chinanteco & 2.8 & 2.3 & 3.4 \\
\hline Mixteco & 2.9 & 2.6 & 3.1 \\
\hline Zoque & 2.9 & 2.3 & 3.7 \\
\hline Tojolabal & 3.0 & 2.0 & 4.6 \\
\hline Maya & 3.1 & 2.6 & 3.6 \\
\hline Popoluca & 3.1 & 2.2 & 4.7 \\
\hline Mazateco & 3.2 & 2.9 & 3.6 \\
\hline Totonaco & 3.2 & 2.8 & 3.7 \\
\hline Tepehuano del Sur & 3.3 & 2.5 & 4.4 \\
\hline Huichol & 3.3 & 2.7 & 4.1 \\
\hline Tarahumara & 3.4 & 2.8 & 4.1 \\
\hline Tzotzil & 3.4 & 3.1 & 3.8 \\
\hline Huasteco & 3.4 & 3.0 & 3.9 \\
\hline Tzeltal & 3.9 & 3.3 & 4.6 \\
\hline
\end{tabular}

Nota: L.I.: límite inferior; L.S.: límite superior.

Fuente: Cálculos propios con base en la Encuesta Intercensal 2015 (INEGI, 2015). 


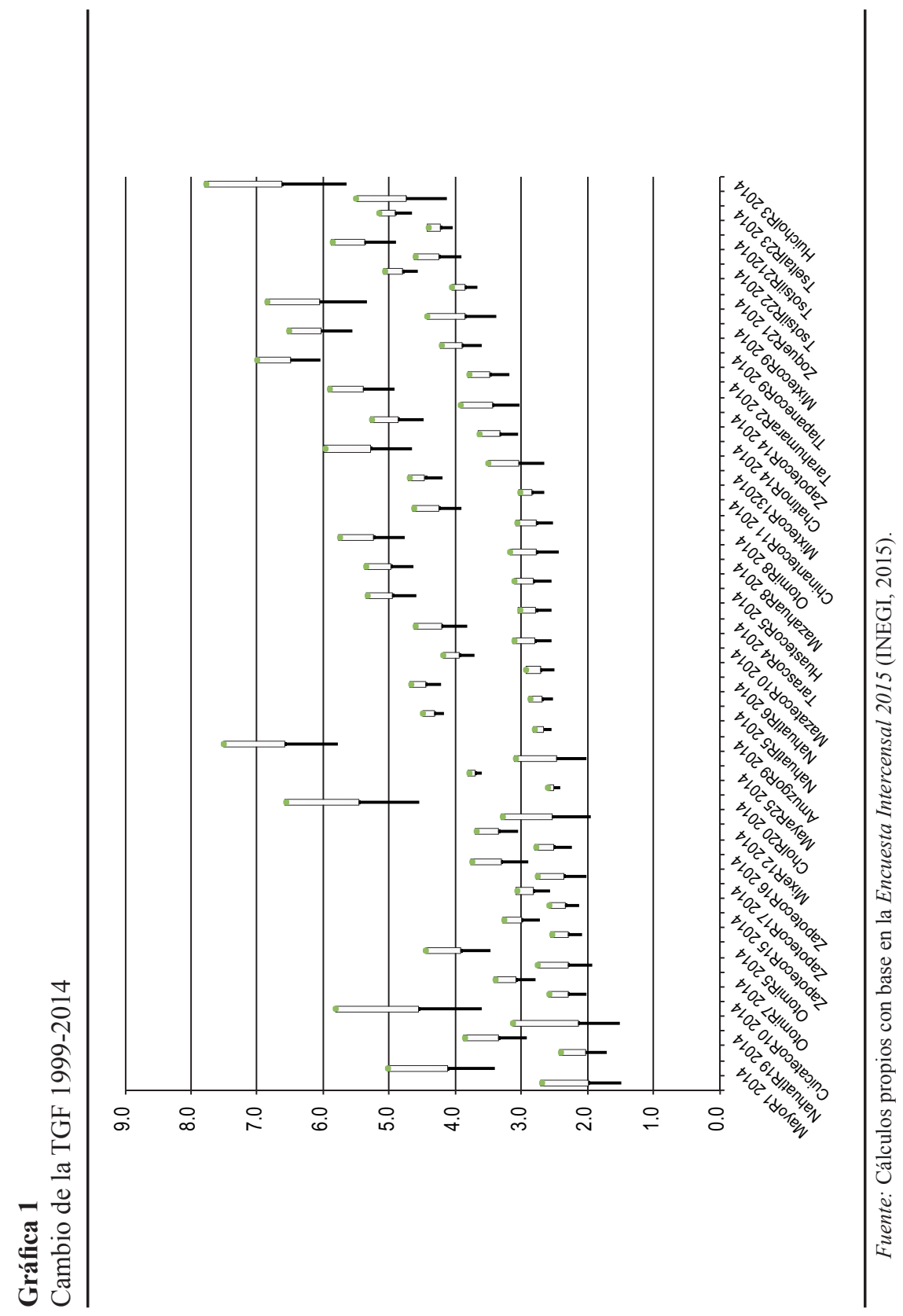


las reducciones porcentuales más notables serían las siguientes: los amuzgos de la Montaña de Guerrero, de más del doble (108\%); los tlapanecos de la Montaña de Guerrero, 64\%; los otomíes de la región Mazahua-Otomí, 57\%; los huastecos de La Huasteca 56\%; y los mazahuas de la Mazahua-Otomí, $56 \%$. Este acelerado descenso de la fecundidad debe ser observado desde el enfoque de los derechos reproductivos en búsqueda de cualquier forma de coerción para inducir a la aceptación del uso de métodos anticonceptivos.

Respecto a los grupos étnicos que presentan un lento descenso en el nivel de la fecundidad durante el periodo de 15 años estudiado, pueden ser agrupados en dos segmentos que vale la pena diferenciar analíticamente: aquellos que, desde la estimación más conservadora mencionada antes, mantienen una baja fecundidad, y los que mantienen una alta fecundidad. En el caso de los primeros, los otomíes de región Otomí y los zapotecos de los Valles Centrales, la Sierra Juárez de Oaxaca y el Istmo de Oaxaca pueden haber alcanzado un nivel avanzado en la transición de la fecundidad. En el caso de los segundos, los huicholes de la Huicot o Gran Nayar, tseltales de la Selva Lacandona, y tsotsiles del Norte de Chiapas, pueden estar en una etapa temprana o pretransicional. Cabe mencionar que el enfoque de derechos también debe estudiar a estos últimos por una posible falta de acceso a los métodos de planificación familiar.

\section{Modelo logístico}

Se ajustó un modelo logístico para predecir los nacimientos ocurridos en 2014 con la finalidad de validar la hipótesis de que el grupo étnico tuviera una especificidad en la explicación de la fecundidad. Se incluyeron como variables explicativas 85 grupos indígenas, en los que se incorporaron 56 grupos étnicos y 29 grupos etnolingüísticos. El objetivo de estudiar estos dos grupos en el modelo es el de validar la tesis culturalista, bajo la cual la cultura es un determinante del comportamiento reproductivo. Estos dos grupos indígenas son empleados como variables proxi para comparar el nivel de conservación y reproducción de la cultura propia: el grupo étnico como mayor nivel y el grupo etnolingüístico como menor nivel. Lo anterior está sustentado en que los grupos étnicos son comunidades territorialmente definidas por residir en regiones tradicionales, por lo que, tal como lo señala la literatura, se espera que conserven y reproduzcan más intensamente su cultura propia. Por su parte, es de esperar que los grupos etnolingüísticos conserven en menor medida e intensidad su cultura propia debido a que viven fuera de sus regiones tradicionales, ya sea que residan en ciudades o en el 
campo, en comunidad o dispersos, y muchos de ellos como emigrantes fuera de sus lugares de origen.

La regla de decisión para la hipótesis de la especificidad de los grupos étnicos en la fecundidad consiste en aceptar que tienen una especificidad sobre la fecundidad; los grupos étnicos no pierden significancia estadística en el modelo junto con las once variables explicativas. Por lo que toca a la hipótesis culturalista, se acepta si la proporción de los grupos étnicos que conservaron significancia estadística en el modelo es superior a la de los grupos etnolingüísticos. Tal vez esta prueba no permita una conclusión categórica respecto a la influencia de la cultura en la fecundidad, pero aporta elementos de prueba.

En el Cuadro 5 puede apreciarse que, de los 85 grupos indígenas incluidos en el modelo, 27 conservaron significancia estadística una vez controlado el efecto de las demás variables intervinientes: 18 de ellos son grupos étnicos y 9 son etnolingüísticos. Esto significa que $32 \%$ de los grupos étnicos y $31 \%$ de los grupos etnolingüísticos que entraron al modelo conservaron significancia estadística, por lo que, bajo los supuestos antes descritos, no puede asegurarse que sea la cultura el factor distintivo de un comportamiento reproductivo propio. De estos 27 grupos, 24 aumentan las razones de momios de la ocurrencia de un nacimiento en 2014, mismos que presentaron TGF superiores al promedio nacional de 2.2 hijos por mujer y 21 de ellos resultaron superiores al promedio de las regiones indígenas de 3.1 hijos por mujer; sólo los nahuas de la región Huasteca y de fuera de las regiones indígenas, así como los mixes fuera de las regiones indígenas, reducen dichas razones de momios; estos últimos presentaron una TGF de apenas 1.7 hijos por mujer.

Cabe mencionar que, de los 60 grupos indígenas que perdieron significancia estadística en el modelo logístico, 35 lo hicieron aun sin agregar ninguna otra variable al modelo (por ello no figuran en el Cuadro 5): 23 de ellos fueron grupos con un reducido número de efectivos en la muestra, lo que explica en parte su baja significancia estadística. De estos 60 grupos indígenas, 11 redujeron las razones de momios asociadas a la fecundidad.

Por lo que toca a la variable de identificación indígena, residir en una zona indígena conserva la significancia estadística y reduce la razón de momios de un nacimiento. Las variables demográficas cumplen la función que se esperaba de ellas en lo que toca a la edad y la unión. Las variables socioeconómicas también tienen el efecto que se podía anticipar de ellas. Entre ellas destaca la variable ser ama de casa. Controlando por las variables incluidas en el modelo, la razón de momios de que una persona que se dedica a los quehaceres del hogar tenga un hijo en 2014 es 1.86 veces mayor 


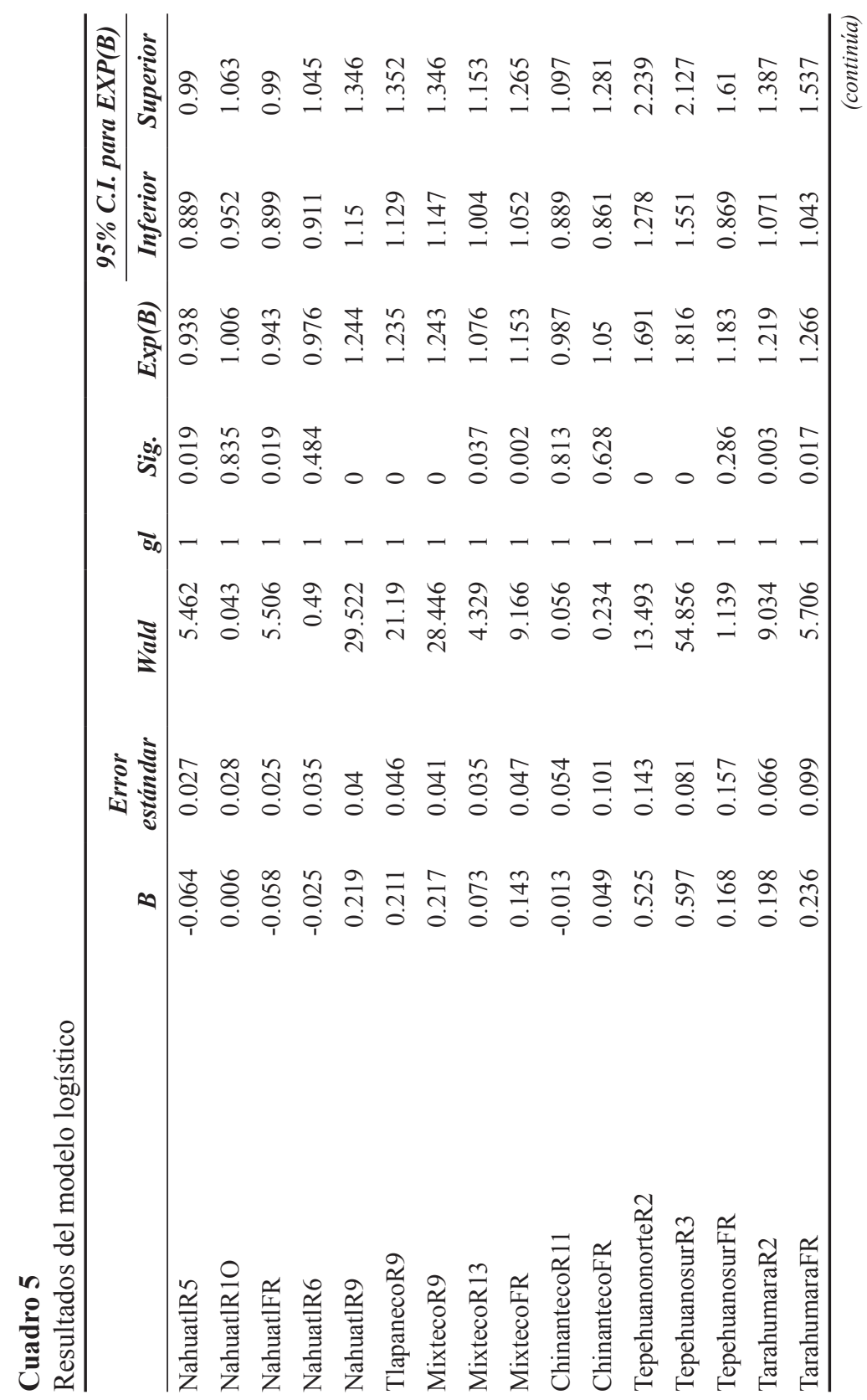




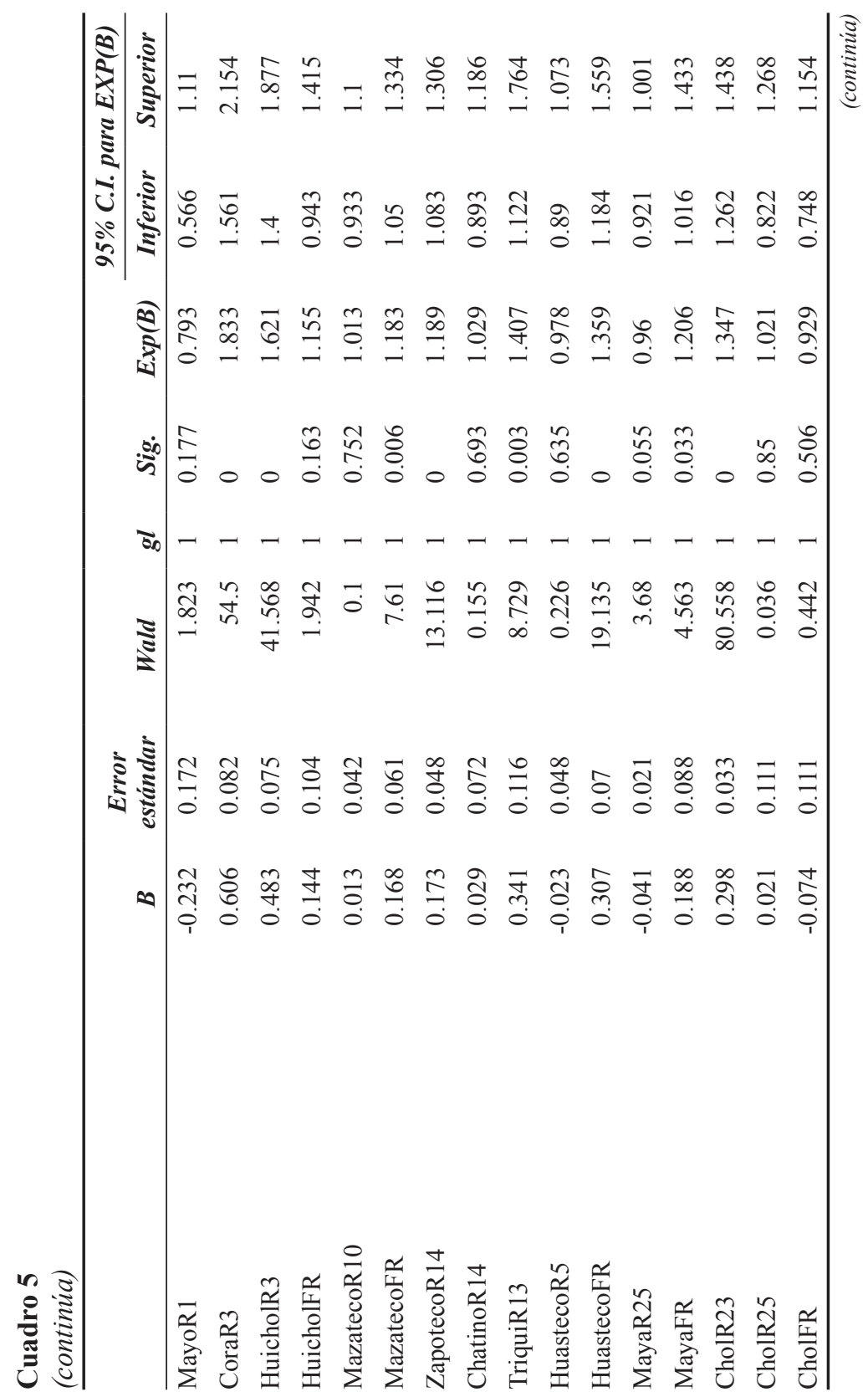




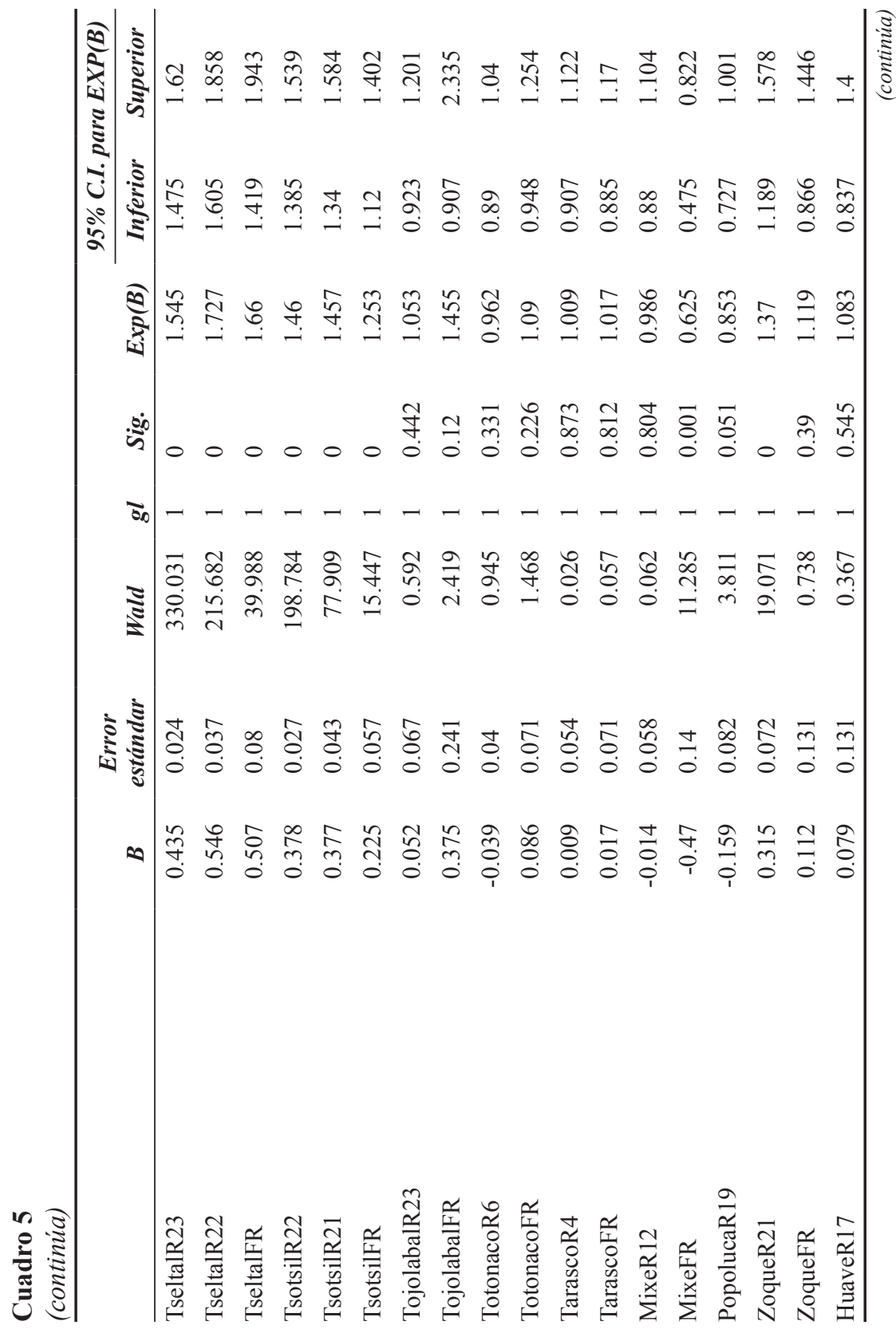




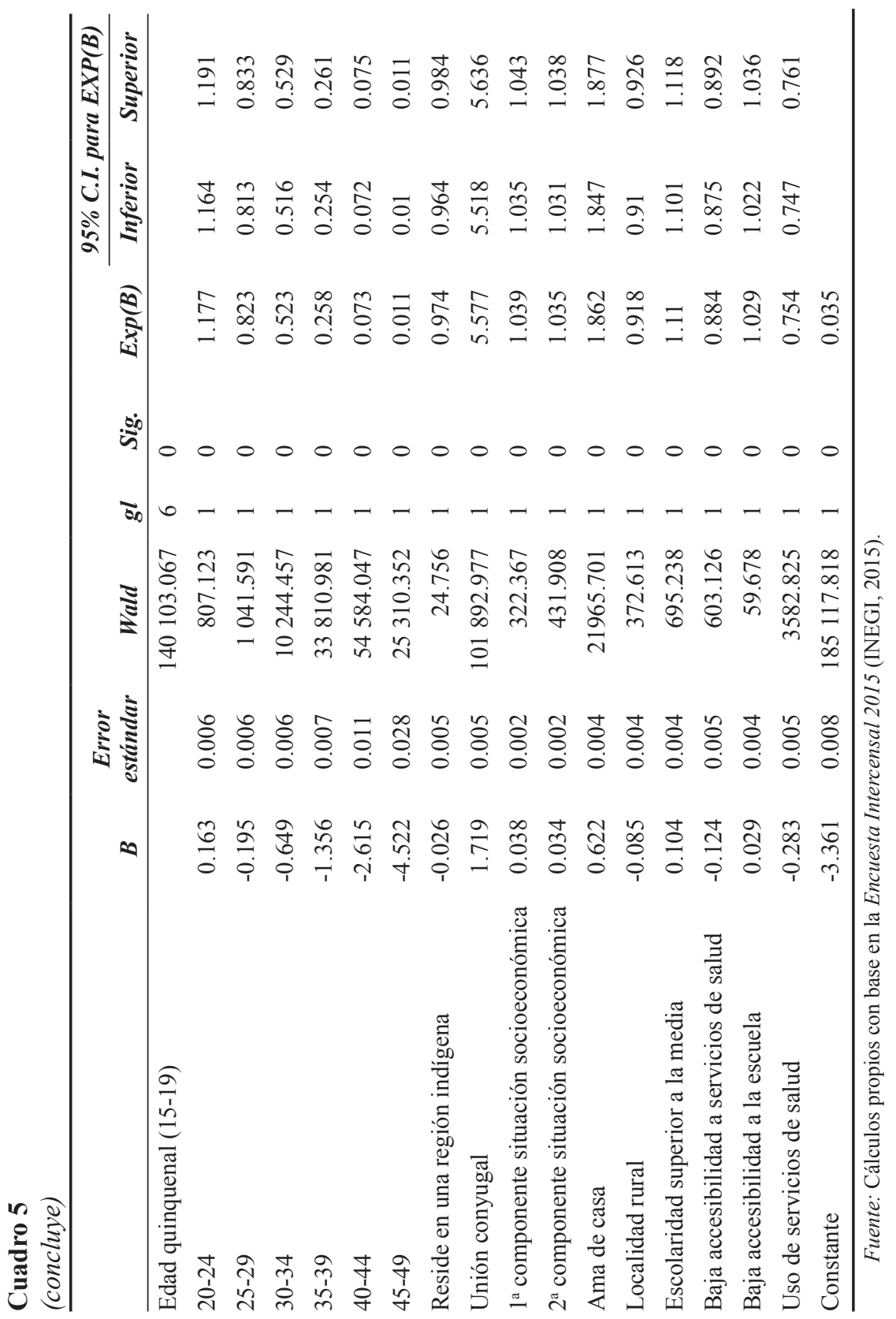


que la razón de momios de que lo tenga una persona que no se dedique a los quehaceres del hogar. El efecto no esperado en este conjunto de variables lo presentó residir en el medio rural, que reduce la razón de momios, y la escolaridad de diez años o más, que la incrementa. Finalmente, las variables de acceso a servicios muestran resultados previsibles, salvo por lo que respecta a la baja accesibilidad a los servicios de salud, que reduce la razón de momios. Una explicación de los resultados inesperados es la vulnerabilidad de la población rural residente en regiones indígenas y con baja escolaridad ante la política de planificación familiar combinada con la medicalización del parto y la frecuencia de la práctica de la cesárea, que ha llevado a una veloz caída de la fecundidad entre estas poblaciones.

\section{Conclusiones}

En general, la fecundidad indígena es más elevada que la no indígena en México y se encuentra en proceso de un descenso rápido después de la mitad de los años 1980. El análisis muestra que dicha convergencia está acompañada de la pérdida de diversidad en los niveles de fecundidad entre regiones indígenas. Sin embargo, el análisis por grupos étnicos permite descubrir lo que las categorías más gruesas esconden. La escala desagregada de la población indígena en 2015 pone en evidencia un rango de variación de la fecundidad cuatro veces más grande que el del tamaño de localidad de residencia habitual, y siete veces mayor que el del analfabetismo.

Una escala fina muestra también los casos atípicos de niveles de fecundidad muy elevada, como el de los coras de la región Huicot (5.6 hijos por mujer), similar a los de Burkina Faso en el periodo 2010-2015, o de bajos niveles como los mayos de la región Mayo-Yaqui, que es idéntica a la de Francia en 2010-2015, o aún más baja, la fecundidad de los mixes fuera de las regiones indígenas (1.7 hijos por mujer), similar a la de Dinamarca, Finlandia y Países Bajos, entre otros.

Asimismo, se encontró que existe mayor diversidad de TGF entre regiones para las mismas lenguas indígenas que entre lenguas indígenas en el interior una misma región, lo cual apunta a que la región indígena sea un factor más importante para determinar el comportamiento reproductivo que la lengua. En términos de la transición de la fecundidad, se encontraron diferentes estadios (pretransicional, transicional y postransicional), dependiendo del grupo étnico. Se observó un muy acelerado descenso de los niveles de la fecundidad entre 1999 y 2014 en varios grupos étnicos, como son: los amuzgos de la Montaña de Guerrero, de más del doble (108\%); los 
tlapanecos de la Montaña de Guerrero, 64\%; los otomíes de la región Mazahua-Otomí, 57\%; los huastecos de la Huasteca, 56\%; los mazahuas de la Mazahua-Otomí, $56 \%$, que están en un proceso propiamente transicional. En el otro extremo, se observó un descenso reducido entre dos tipos de grupos étnicos; algunos con baja fecundidad, como son: los otomíes de región Otomí, los zapotecos de Valles Centrales, Sierra Juárez de Oaxaca e Istmo de Oaxaca, quienes pueden haber alcanzado un nivel avanzado en la transición de la fecundidad; y en grupos con elevada fecundidad: los huicholes de la Huicot o Gran Nayar, los tzeltales de la Selva Lacandona, los tzotziles del Norte de Chiapas, que se encuentran en una etapa temprana o incluso pretransicional.

El modelo logístico permitió validar la hipótesis según la cual la población indígena tiene una especificidad en términos de fecundidad para 27 grupos étnicos, a saber: de la región Huicot o Gran Nayar, tepehuanos del sur, coras y huicholes; de la Selva Lacandona, choles y tzeltales; de la Montaña de Guerrero, mixtecos, nahuas y tlapanecos; de la Mixteca, mixtecos y triquis; de la Tarahumara, tarahumaros y tepehuanos del norte; de los Altos de Chiapas, tzeltales y tzotziles; del Norte de Chiapas, zoques y tzotziles; de la Sierra del Sur de Oaxaca, zapotecos; de La Huasteca, nahuas; y fuera de las regiones indígenas, nahuas, huastecos, mayas, mazatecos, mixes, mixtecos, tarahumaras, tzotziles y tzeltales.

Adicionalmente a la comprobación de la hipótesis, este conjunto de grupos indígenas dentro y fuera de las regiones indígenas es de gran interés para futuras investigaciones. No es posible asegurar, sin embargo, que la especificidad de estos grupos sobre su fecundidad tenga una explicación de tipo cultural; no obstante, esta explicación tampoco ha sido descartada, dado que las variables sociales, demográficas y de accesos a los servicios de salud fueron controladas.

Algunos resultados no esperados del modelo logístico son que la escolaridad superior a la media nacional aumenta las razones de momios de la ocurrencia de un nacimiento en 2014, y que, por el contrario, residir en una localidad rural, residir en una región indígena tradicional y hablar una lengua indígena (si bien esta última careció de significancia estadística) los reduce. Esto, aunado con el rápido descenso de muchos de los grupos étnicos de México en el periodo 1999-2014, puede ser explicado por los efectos de la política de planificación familiar, combinada con la medicalización del parto y la frecuencia de la práctica de la cesárea, lo cual debe ser investigado con detenimiento desde la perspectiva de los derechos reproductivos. 


\section{Bibliografía}

Bartolomé, M. (coord.). (1997). Gente de costumbre y gente de razón. Las identidades étnicas en México. Ciudad de México: Siglo XXI.

Beck, U. (2014). Nationalisme méthodologique-cosmopolitisme méthodologique: Un changement de paradigme dans les sciences sociales. Raisons Politiques, 2(54), 103-120. Recuperado de https://www.cairn.info/revueraisons-politiques-2014-2-page-103.htm

Cámara de Diputados del Honorable Congreso de la Unión. (2019). Constitución Política de los Estados Unidos Mexicanos. Recuperado de http:// www.diputados.gob.mx/LeyesBiblio/pdf/1_060619.pdf

Chávez, A., Hernández, H., Menkes, C. y González, E. (2007). Tendencias de la fecundidad indígena en México, 1997 y 2003. En H. H. Hernández Bringas (coord.), Los indios de México en el siglo XXI (pp. 43-60). Cuernavaca: UNAM, Centro Regional de Investigaciones Multidisciplinarias.

Cleland, J. y Wilson, C. (1987). Demand theories of the fertility transition: An iconoclastic view. Population Studies, 41(1), 5-30. Recuperado de https://www.jstor.org/stable/2174324?seq=1\#page_scan_tab_contents

Comisión Nacional para el Desarrollo de los Pueblos Indígenas, Programa de Naciones Unidas para el Desarrollo (2006). Regiones indígenas de México. Ciudad de México: CDI / PNUD. Recuperado de http://www. cdi.gob.mx/regiones/regiones_indigenas_cdi.pdf

Dehouve, D. (2001). Ensayo de geopolítica indígena. Los municipios tlapanecos. Ciudad de México: Centro de Investigaciones y Estudios Superiores en Antropología / Miguel Ángel Porrúa.

Díaz-Polanco, H. (2009). Diez tesis sobre identidad, diversidad y globalización (Documento de investigación). Ciudad de México: Centro de Investigaciones y Estudios Superiores en Antropología Social (CIESAS). Recuperado de http://data.over-blog-kiwi.com/1/38/03/91/20150928/ ob_8eb56c_diez-tesis-sobre-identidad-diversidad.pdf

Giménez, G. (1997). Materiales para una teoría de las identidades sociales. Frontera Norte, 9(18), 9-28. Recuperado de https://fronteranorte.colef. $\mathrm{mx} /$ index.php/fronteranorte/article/viewFile/1441/891

Gros, C. (2012). Políticas de la etnicidad: identidad, estado y modernidad. Bogotá: Instituto Colombiano de Antropología e Historia.

Hammel, E. A. (1990). A theory of culture for Demography. Population and Development Review, 16(3), 455-485. Recuperado de https://www.jstor. org/stable/1972832?seq=1\#page_scan_tab_contents

INEGI (2015), Encuesta Intercensal 2015. Aguascalientes, México: Instituto Nacional de Estadística y Geografía. 
Kertzer, D. I. (1995). Political-economic and cultural explanations of demographic behavior. En S. Greenhalg (ed.), Situating fertility. Anthropology and demographic inquiry (pp. 29-52). Cambridge: University Press. Knodel, J. y Van de Walle, E. (1979). Lessons from the past: Policy implications of historical fertility studies. Population and Development Review, 5(2), 217-245. Recuperado de https://www.jstor.org/stable/197 1824 ?seq=1\#page_scan_tab_contents

Martínez-Cobo, J. R. (1987). Estudio del problema de la discriminación contra las poblaciones indigena. Nueva York: Naciones Unidas.

Partida, V. y Solís, P. (1997). La población indígena. En Conapo (coord.), La situación demográfica de México, 1997 (pp. 73-81). Ciudad de México: Consejo Nacional de Población.

Schoumaker, B. (2004). Une approche personnes-périodes pour l'analyse des histoires génésiques. Population, 59(5), 783-796. Recuperado de https://www.cairn.info/revue-population-2004-5-page-783.htm?contenu= resume

Stavenhagen, R. (1992). La cuestión étnica: algunos problemas teórico-metodológicos. Estudios Sociológicos, 10(28), 53-76. Recuperado de http:// estudiossociologicos.colmex.mx/index.php/es/article/view/925/925

Telles, E. (2014). Pigmentocracies. Ethnicity, race, and color in Latin America. Chapel Hill: The University of North Carolina Press.

United Nations (1983). Study of the problem of discrimination against indigenous population (Documento de trabajo, núm. E/CN.4/Sub.2/1983/21/ Add.8). Recuperado de https://www.un.org/esa/socdev/unpfii/docu ments/MCS_xxi_xxii_e.pdf

United Nations (2015). World population prospects. Key finding and advance tables (Documento de trabajo, núm. ESA/P/WP.241). Recuperado de https:// esa.un.org/unpd/wpp/publications/files/key_findings_wpp_2015.pdf

Vázquez, G. (2010). Fecundidad indígena. México: Universidad Autónoma del Estado de Hidalgo / Miguel Ángel Porrúa.

Vázquez, G. (2012). La transición de la fecundidad indígena urbana en México. En A. Ortiz y G. Vázquez (coords.), Estudios Demográficos del Estado de Hidalgo, tomo 4 (pp. 35-46). México: Universidad Autónoma del Estado de Hidalgo.

Vázquez, G. (2013). Dinámica demográfica de las poblaciones indígenas en México: 1970-2010. En L. M. Valdés (coord.), Hacia una nueva Ley General de Población (pp. 237-258). Ciudad de México: UNAM.

Vázquez, G. (2016). Poblaciones indígenas urbanas en México y su comportamiento reproductivo. En M. Coubès, P. Solís y M. E. Zavala de 
Cosío (coords.), Generaciones, curso de vida y desigualdad social en México (pp. 77-108). Ciudad de México: El Colegio de México, A.C. Vázquez, G. y Cenobio, F. (2017). Tendencias recientes de la fecundidad de las mujeres hablantes de lengua indígena en México. Ponencia presentada en el Sexto Congreso Internacional de Investigación Social. Pachuca, Hgo.: Universidad Autónoma del Estado de Hidalgo.

Wade, P. (1997). Race and ethnicity in Latin America. Sidmouth: PlutoPress. Wade, P. (2008). Race in Latin America. En D. Poole (ed.), A companion to Latin American anthropology (175-192). Chichester, Inglaterra: Blackwell.

\section{Acerca del autor}

Germán Vázquez Sandrin es profesor-investigador de la Universidad Autónoma del Estado de Hidalgo. Es licenciado en Sociología por la Universidad Nacional Autónoma de México, ENEP Acatlán; maestro en Estudios de Población por la Facultad Latinoamericana de Ciencias Sociales y doctor en Estudios de las Sociedades Latinoamericanos por la Universidad de la Nueva Sorbona (París 3). Ha publicado varios libros, capítulos de libro y artículos en revistas especializadas. Sus líneas de investigación se centran en temas de la demografía étnica, particularmente: fecundidad, dinámica demográfica, curso de vida e identificación indígena. Es miembro del Sistema Nacional de Investigadores (SNI) y coordinador de la Red Mexicana de Estudios sobre Poblaciones Indígenas, desde su fundación en 2007. ORCID: https://orcid.org/0000-0003-4319-7707

Su libro más reciente es:

Vázquez, G. (2018). Diagnóstico participativo de las poblaciones indígenas del estado de Hidalgo. Hacia la conformación de un Programa Estatal de Población Indigena. Pachuca: Universidad Autónoma del Estado de Hidalgo.

Recepción: 11 de marzo de 2018.

Aceptación: 22 de mayo de 2018. 